\title{
New insights into the methods for predicting ground surface roughness in the age of digitalisation
}

\author{
Yuhang Pan ${ }^{\mathrm{a}}$, Ping Zhou ${ }^{\mathrm{a} *}$, Ying Yan ${ }^{\mathrm{a}}$, Anupam Agrawal ${ }^{\mathrm{b}}$, Yonghao Wang ${ }^{\mathrm{a}}$, \\ Dongming Guo and Saurav Goel ${ }^{\mathrm{c}, \mathrm{de}, \mathrm{e}, \mathrm{f}}$ \\ ${ }^{a}$ Key Laboratory for Precision and Non-traditional Machining Technology of Ministry of Education, \\ Dalian University of Technology, Dalian 116024, China \\ ${ }^{b}$ Mays Business School, Texas A\&M University, College Station, TX, USA \\ ${ }^{c}$ School of Engineering, London South Bank University, 103 Borough Road, London SE1 0AA, UK \\ ${ }^{d}$ School of Aerospace, Transport and Manufacturing, Cranfield University, Bedfordshire, MK43 \\ $O A L, U K$ \\ ${ }^{e}$ Department of Mechanical Engineering, Shiv Nadar University, Gautam Budh Nagar, 201314, \\ India \\ ${ }^{f}$ EPSRC Centre for Doctoral Training in Ultra-Precision Engineering, University of Cambridge \\ and Cranfield University, UK
}

\begin{abstract}
Grinding is a multi-length scale material removal process that is widely employed to machine a wide variety of materials in almost every industrial sector. Surface roughness induced by a grinding operation can affect corrosion resistance, wear resistance, and contact stiffness of the ground components. Prediction of surface roughness is useful for describing the quality of ground surfaces, evaluate the efficiency of the grinding process and guide the feedback control of the grinding parameters in real-time to help reduce the cost of production. This paper reviews extant research and discusses advances in the realm of machining theory, experimental design and Artificial Intelligence related to ground surface roughness prediction. The advantages and disadvantages of various grinding methods, current challenges and evolving future trends considering Industry-4.0 ready new generation machine tools are also discussed.
\end{abstract}

Keywords: Industry-4.0; digitalization; Quality; Prediction; Digital manufacturing; Precision grinding

*Corresponding author, email: pzhou@dlut.edu.cn 


\section{Abbreviations:}

ACO Ant Colony Algorithm

AI Artificial intelligence

ANNs Artificial Neural Networks

ANFIS Adaptive network-based fuzzy inference system

ANOVA Analysis of variance

BPNN Back propagation neural network

DEM Discrete element method

Des Discrete elements

DoE Design of experiments

ELID Electrolytic in-process dressing

FEA Finite element analysis

FES Fuzzy Expert Systems

GA Genetic algorithm

GPR Gaussian regression function

IBRs Integrally bladed rotors

MNLR Multi Non-Linear Regression

PSO Particle Swarm Optimization

RSM Response Surface Methodology

S/N Signal-to-noise

SVM Support vector machines

TTV Total thickness variation

\section{Nomenclature:}

$a_{e}$ Grinding depth

$a_{j-1}$ Actual depth of cut of the $(j-1)_{\text {th }}$ grit

$a_{j}$ Actual depth of cut of the $j_{\text {th }}$ grit

$B$ Longitudinal distance between two adjacent grits

c The constant or intercept

$C$ Grit number per unit area 
$d_{e}$ Diameter of wheel

$L \quad$ Lateral distance between two adjacent grits

$r$ Chip width-to-thickness ratio

$R_{\mathrm{a}}$ Average surface roughness

$v_{\mathrm{w}}$ Workpiece infeed speed

$v_{\mathrm{s}}$ Wheel speed

$\delta_{\mathrm{n}}$ Undeformed chip thickness caused by the difference in height of the adjacent grits

$\varepsilon_{i}$ estimation error of the model

$\theta \quad$ Semi-included angle for the undeformed chip cross-section

$\sigma$ A parameter that completely defines the probability density function

\section{Introduction}

Grinding is a displacement or position-controlled processing method where the excess material from the workpiece surface is removed by using an abrasive tool. The advantages of this important precision machining technology over other processing methods such as turning and milling include high material removal rate, better surface finishes and longer production runs. With the incorporation of electrolytic in-process dressing (ELID), self-dressing of the wheel is possible to achieve a longer tool life. Grinding is now being increasingly used in the processing of high precision parts $[1,2]$ and to machine 'difficult to cut' glass ceramics [3,4], particularly for the large science programs requiring Precision-at-scale fabrication of telescope mirrors. Ground surface quality is governed by many factors e.g. process variables, loop stiffness, environment, stochastic distribution of the abrasive grits on the grinding wheel). Researchers have therefore long been working to develop predictive models to analyze the effect of grinding parameters on the surface topography [5] as well as the grinding wheel and workpiece properties [6].

Surface roughness has a significant impact on the service life and reliability of mechanical products as it can directly affect the tribological conditions and thus the corrosion, wear, fatigue and similar other attributes of the workpiece [7]. Ground surface roughness depends on interactions of a multitude of factors $[8,9]$ and these 
interactions depend on the process parameters of grinding, properties of the processed material and the grinding wheel. Predictive values of the ground surface roughness can guide the design of machine tools to make them Industry 4.0 compliant which will eliminate the downstream material wastage and excessive generation of grinding sludge $[10]$.

This review article aims to provide new insights into the methods and strategies for predicting the roughness of ground surfaces. We review, analyze, and categorize extant research to provide detailed insights into the state-of-the-art and identify future research directions, thus providing a comprehensive reference for ground surface roughness prediction, especially considering the digitalisation tools currently available. This paper is organized as follows. In Section 2, we present the classification of ground surface roughness prediction models. We review methods based on the machining theory in Section 3. We present a review of prediction models based on the experimental design and analysis in Section 4. In Section 5, we discuss artificial intelligence (AI) methods that can be used to make the grinding process more robust and resilient. We discuss current challenges and future trends for predicting the ground surface roughness in Section 6 and conclude by offering remarks on the latest developments in Section 7.

\section{Classification of ground surface roughness prediction models}

In recent years, many surface roughness prediction models have been developed and these have largely remained focused on grinding parameters [11]. Tönshoff [12] subdivided the models describing the grinding process into physical and empirical models and compare the principles and applications of the two approaches shown in Fig. 1.

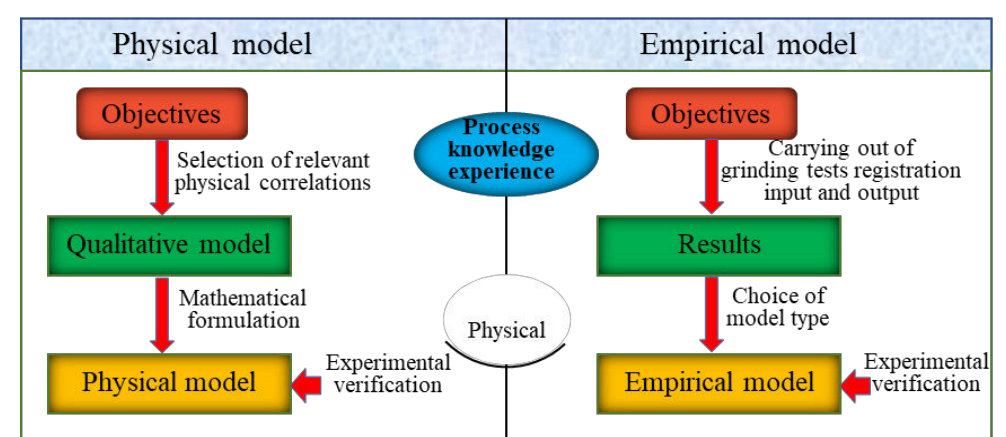

Fig. 1. The comparison of the physical model and the empirical model [12]. 
More than a decade ago, Brinksmeier et al. [13] reviewed the advances in modelling and simulation of grinding processes by focusing on ground surface topography, surface integrity, etc.. They categorized various models into physical process models (analytical and numerical models), empirical process models (regression analysis, artificial neural network models) and heuristic process models (rule-based models). They highlighted the uniqueness of each model as well as its limitations. Taking Tönshoff's and Brinksmeier's classification into consideration we propose to classify the grinding roughness prediction models into three major categories as follows:

(i) Theoretical models based on machining theory: These models discuss and develop methods based on numerical and/or analytical techniques. Numerical simulation models generally focus on the microscopic interactions of the abrasive grit and the workpiece to estimate the surface roughness. Analytical models of surface roughness are usually based on grinding kinematic geometry and establish a correlation between chip thickness and surface roughness. Such heuristic models are largely driven by our understanding of the engineering processes, in particular by the known physics of materials behaviour (e.g., plastic deformation under given stress states).

(ii) Regression models based on experimental design and analysis: These models focus on the prediction of surface roughness using experimental design, experimental data processing, and analysis. These statistical models are largely driven by the collected data and subsequent fitting schemes.

(iii) Artificial intelligence-based models: These models try to predict surface roughness by using rigorous data mining and AI algorithms to map the correlations between grinding parameters and surface roughness. AI-based models can be driven either by theoretical physical data or by experimentally collected data and the focus of such models is to recognize a general pattern to identify critical trends.

\section{Methods based on machining theory}

Material removal and chip formation during the grinding process involve 
interaction between the abrasive grits and the workpiece. The stochastic distribution of the abrasive grits leads to multiple levels of engagement between the workpiece and grinding and this poses challenges in the accurate prediction of ground roughness. Research into the prediction of ground roughness has been based on:

(i) Numerical simulations to describe the changes in grinding wheel geometry

(ii) The theory of machining such as process kinematics, cutting tool properties and chip formation mechanism, and

(iii) Statistical models are based on the interaction between the topography of the grinding wheel and the movement of the workpiece.

\subsection{Numerical simulations}

Papers in this category generally use computer-aided design (CAD) methods and tools to build models that can simulate the generation of the surface profile, which can help in visualizing surface topography and in predicting the surface roughness. Fig. 2 depicts a flow chart of the simulation procedure [14]. For carrying out the simulation, the geometry of the grinding wheel and the workpiece as well as the process kinematics needs to be modelled, and then the chip parameters (such as undeformed chip thickness $h_{\mathrm{m}}$, chip length $l_{\mathrm{cu}}$, and chip width $b_{\mathrm{cu}}$ can be obtained by the interaction between the grinding wheel and workpiece. Also, based on these simulated chip parameters, the specific grinding force and topography of the workpiece surface can be estimated.
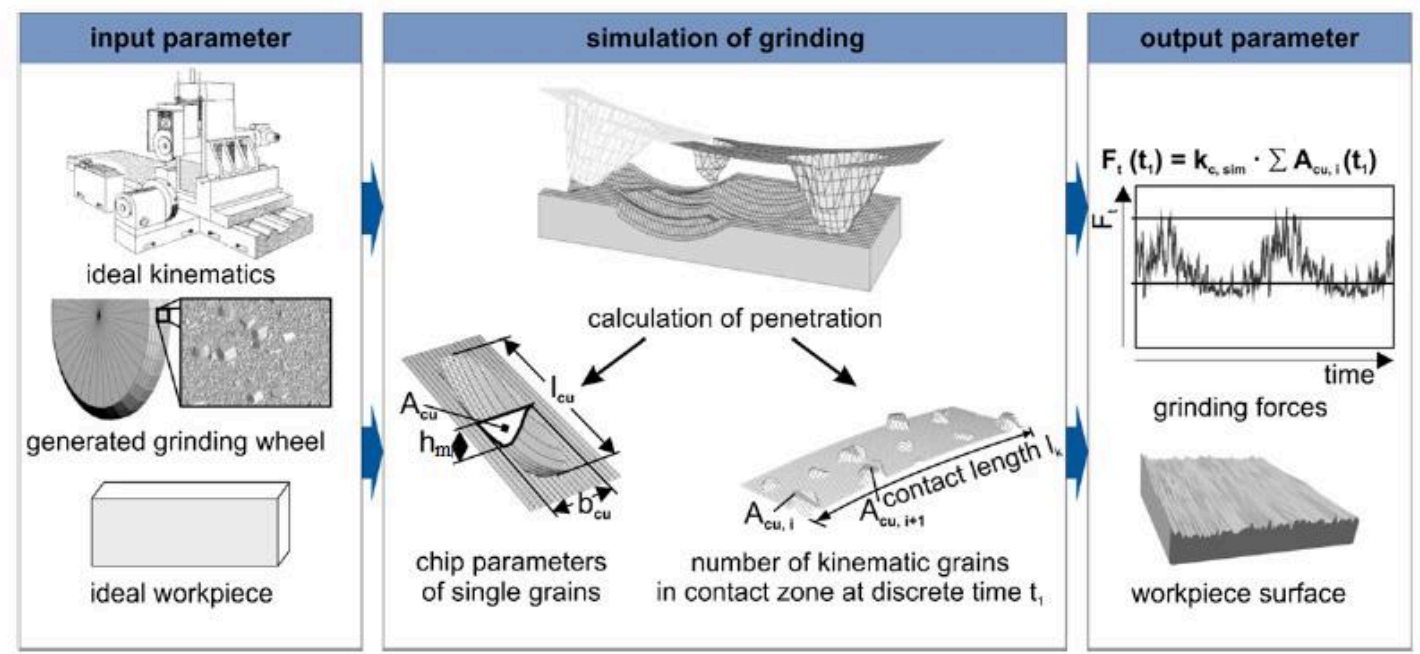

Fig. 2. Flowchart of the Numerical simulations [14]. 
The abrasive grits (usually vitrified or electroplated) of the grinding wheel are the backbone of any grinding process and their performance affects the quality of the machined surface. Therefore, a model predicting the performance of the grits can serve as a guide towards cost-saving experimental trials. The cutting performance of a grinding wheel depends on the grit size, grit geometry and its end radius, distribution of grits and the environment of operation (e.g., coolant). Based on this, many studies have tried to examine the effects of the grit protrusion height, shape, size, distribution and kinematical cutting path. Kassen et al. $[15,16]$ first proposed the use of kinematicgeometric modelling to determine the surface roughness during grinding and predicted it by developing two-dimensional grit models. Koshy et al. [17] developed a threedimensional grinding layer model comparing actual and simulated roughness values in different workpiece materials and proposed that the ground surface roughness was largely dominated by the abrasive grit protrusions. Gong et al. [18] simulated the surface topography of the workpiece for predicting ground surface roughness. In the methods proposed by them, the surface of the grinding wheel was proposed to be composed of spherical grinding grits and the effect of the grinding wheel parameters (including grit size and distribution, wheel structure and material) and grinding parameters on surface topography generation was considered. Liu et al. [19] considered three different abrasive grit shapes (sphere, truncated cone and cone, as shown in Fig. $3 \mathrm{a})$ to predict workpiece surface roughness in grinding. From their work, the $3 \mathrm{D}$ wheel model with 2D cutting edge profiles was obtained (Fig. 3b). Their results showed that the main parameters affecting the resulting workpiece surface are the dressing parameters (the geometry of the diamond tip, the dressing depth of the cut, and the overlap ratio). Wang et al. [20] simulated the abrasive grit distribution in a grinding wheel by using the grit vibration method. They examined the effect of different grinding parameters on the surface topography of the workpiece. Siebrecht et al [21] extended the grinding tool model to predict the surface roughness and the simulated process forces by modelling single diamond grits, which were randomly distributed over the tool and approximated as the intersection of a cube and an octahedron. Chen et al. [22] considered random distribution of the grit protrusion heights and the location. They 
proposed a simulation model to predict the surface roughness of ultrasonic-assisted grinding. They also discussed the effect of the ultrasonic vibration amplitude on surface roughness.

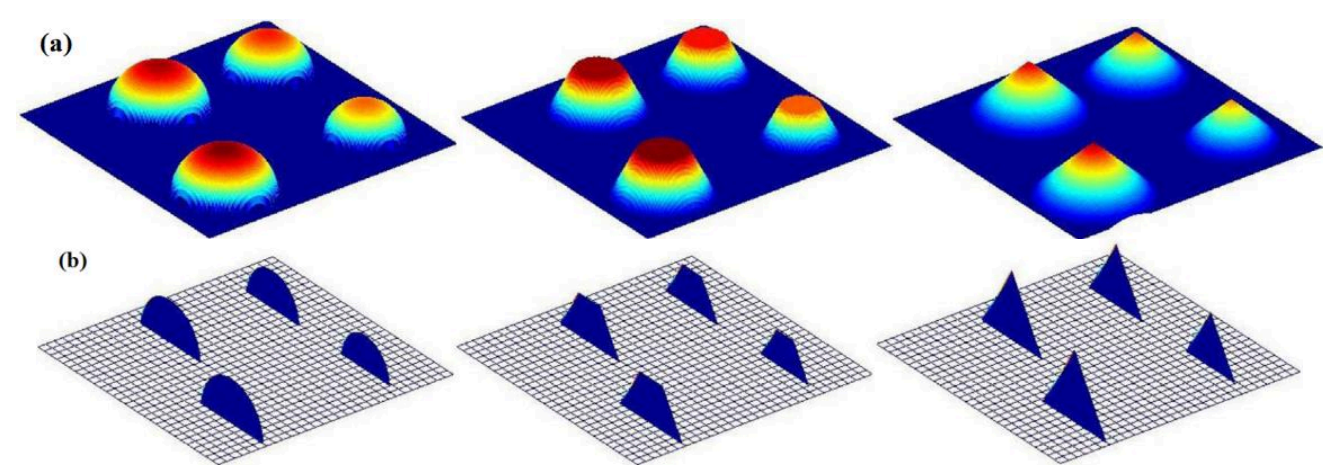

Fig. 3. Simulated grinding results. (a) Modelled 3D grit shapes (b) 2D cutting edge model [19].

The studies outlined above considered grit protrusion height, shape, size, and distribution when developing the wheel model. Many studies added to this stream of literature by considering other parameters. Jiang et al. [23] added wheel dressing and wear effects and used dressing and wear profile lines to describe the changes in the profile of grits. On this basis, they developed a 2D and 3D ground surface topography model based on the grit-workpiece microscopic interaction mechanism. Sun et al. [24] developed a numerical model of the dressed grinding wheel by a single-point diamond pen and generated micro surface topography of the workpiece based on the grinding kinematics. The grinding workpiece surface roughness was obtained by considering the grinding wheel and main machining parameters. The authors also explained the coupling matching relationship between these parameters under ultrasonic-assisted grinding. Chen et al. [25] proposed a simulation method for point grinding based on the combination of selected trajectories to form the 3D workpiece surface. They took into account the surface features of the grinding wheel (including the distribution of the protrusion heights of the cutting points and the grit spacings along with the circumferential and axial directions of the wheel) and the elastic-plastic deformation of the workpiece material when describing the movement path of the abrasive grits. The interference trajectories were screened by iterating over the cutting paths of all grits on the grinding wheel surface, which helped in predicting the surface quality of the 
grinding workpiece.

Li et al. [26,27] divided the existing grinding wheel models into three categories:

(i) empirical grinding wheel model,

(ii) physical grinding wheel model, and

(iii) measurement-based grinding wheel model.

They noted that the existing models were continuum-based, without considering the internal structures of the grinding wheel (e.g., binder and pores) into consideration. They proposed a discontinuous grinding wheel model based on a discrete element method (DEM). In a DEM model, abrasive grits are described by discrete elements (DEs), but rather than being loose, a bond is allowed between the DEs to facilitate a numerical description of the complex grinding wheel structure. Before bond formation or after bond breakage, the interaction between DEs works according to Hertz-Mindlin contact model (HMCM) (Fig. 4a). While bonding (Fig. 4b), if the distance between any two DEs is smaller than the preset critical distance of bond formation, a bond will be built, linking two elements together (Fig. 4c). The bonds and interactions between elements help in examining the macro-scale mechanical properties of the wheel body. Based on this method, they obtained the description of the grinding wheel by determining the modelling region, modelling of abrasive grits, binder and pore. Their novel DEM method has now opened new possibilities in surface roughness prediction. Osa et al. [28,29] proposed a more complex model based on the DEM to predict grinding contact length, grinding forces and surface roughness.
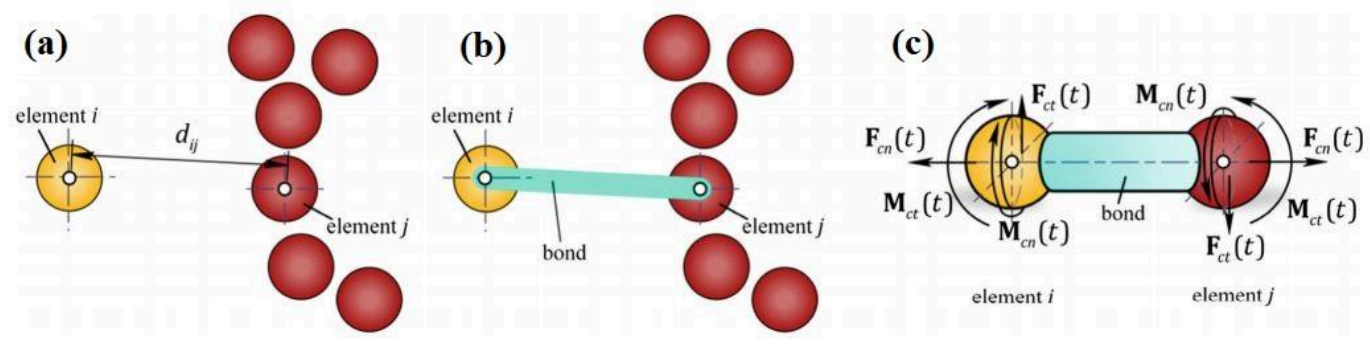

Fig. 4. Schematic diagram of DEM (a) Before bonding (b) bonding and (c) interaction between two linked Des after bonding [26,27].

In addition to the grinding wheel model, another critical issue is to describe the kinematic interactions between the grits and the workpiece. In the grinding contact zone, 
a large number of grits with random geometry and distribution come in contact with the workpiece material. It is generally believed that grit level interactions will involve sliding, ploughing and cutting. In fact, the interaction between grits and workpiece could be very complex depending on various factors such as the workpiece material, grinding wheel, machine tool and process settings. To understand this complexity, Chakrabarti et al. [30] proposed a numerical simulation method to predict the surface roughness of the workpiece wherein the trajectory of all the abrasive grits was obtained by simulating grinding wheel topography. They generated the grinding surface morphology by simulating the kinematic interactions between the workpiece surface and the grinding wheel for different grinding parameters. Chen et al. [31] extended the current understanding on the interaction between the workpiece surface and grinding grits by considering the side flow of the material. However, in their work, ploughing and sliding of the material were neglected. Nguyen and Butler [32] proposed an algorithm for identifying active abrasive grits and the critical values of the attack angle. As shown in Fig. 5, the active grains refer to the grains that have a protruding height more than the surface of the workpiece before cutting and therefore engage with the workpiece during the cutting operation. The authors asserted that only a fraction of grits come in contact with the workpiece during grinding and experience cutting force leading to the chip formation process while others just slide or plough the workpiece surface. Based on the critical values of the attack angle, the abrasive grits were determined to slide, plough, or cut the workpiece.

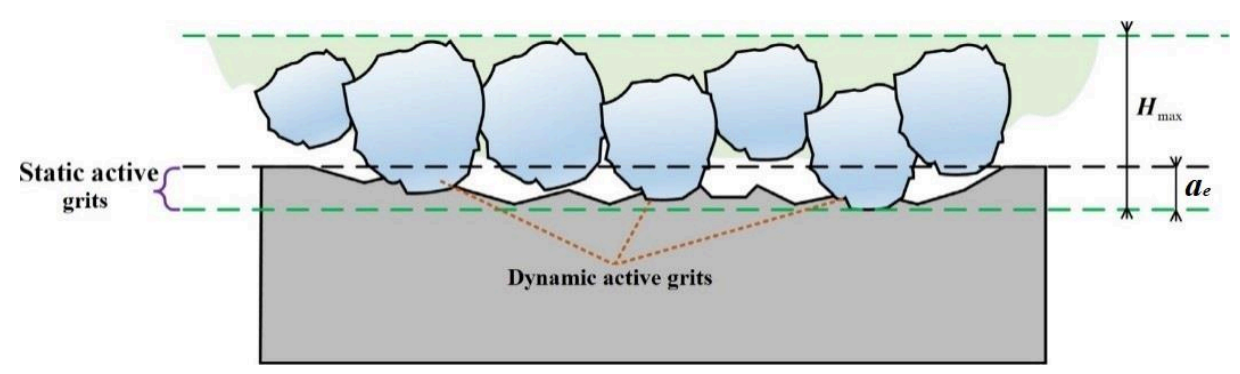

Fig. 5. Schematic diagram of active grits [33].

Chen et al. [34] presented a surface roughness prediction model considering ploughing effect based on the assumption that the shape of abrasive grits was spherical 
and the shape of their profile was parabolic. The area of the remaining material in the whole grinding process was proportional to the area of the spherical grits in the range of cutting depth. Zhou et al. [35] presented a model for predicting the ground surface topography considering the morphology changes of ploughing caused by the interference between adjacent abrasive grits. Fig. 6a. indicates that the material flows and accumulates along with the shape of the workpiece generated by the first abrasive grit. At the interference of the two grits shown in Fig. 6b (left and right), the ploughing separates their (EFG and $\mathrm{ABC}$ ) overlap, indicating that the final profile generation occurs due to both grits. These results showed that the surface topography model is in good agreement with the experimental results and the ploughing effect could not be ignored.

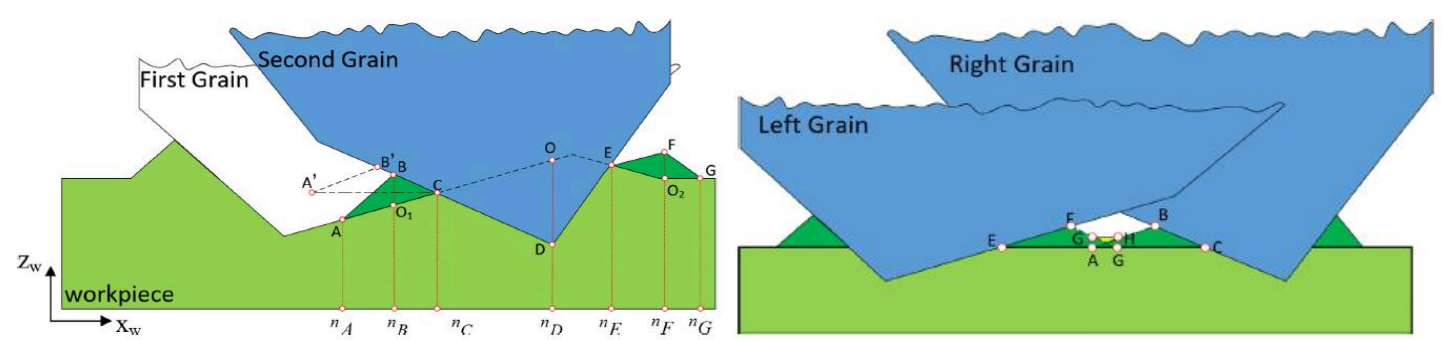

Fig. 6. Schematic of interference of adjacent abrasive grits. (a) the interference of front and rear grits and (b) interference of right and left grits [35].

Hard and brittle materials such as engineering ceramics, optical glasses and semiconductors have been widely used in aerospace, defense, electronics and other high-technology fields. As shown in Fig.7. the interaction between single grit and brittle workpiece material mimics a scratch, revealing two different types of cracks: lateral and median [36]. The definition of surface roughness indicates that the lateral crack $\left(C_{l}\right)$ is the most influential factor governing the surface quality during the so-called ductilemode machining. Wang et al. [37] considered an overlapping path between the adjacent grits when developing the surface roughness prediction model of the rotary ultrasonic grinding. The authors found that the adjacent grits paths will interfere with each other by a separation distance of $2 C_{1}$ (Fig. $\left.8 \mathrm{a}\right)$, and in the same distance, the path interference will strengthen with the increase of the grits number (Fig.8b). They also proposed that grit path overlap will lead to smaller grinding forces and lower surface roughness. 


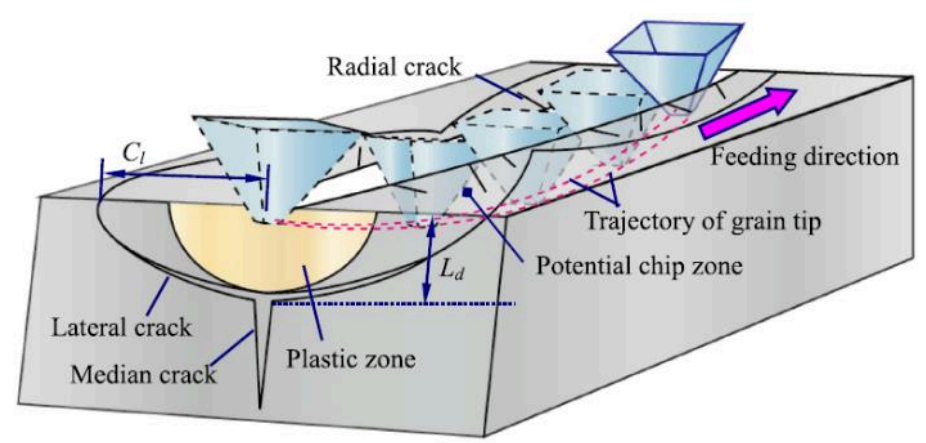

Fig. 7. Fracture in brittle materials during grinding process [36].
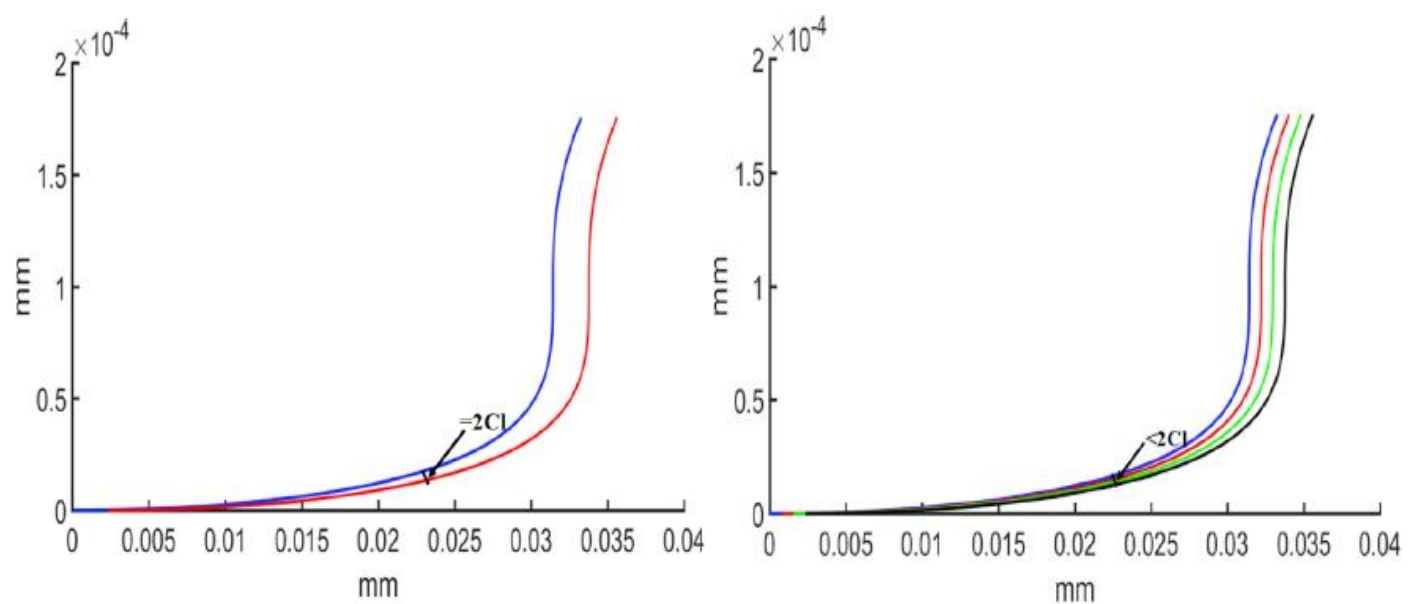

Fig. 8. Adjacent abrasive grit paths interference. (a) Two abrasive grit paths on the critical state and (b) four abrasive grit paths above the critical state [37].

In the grinding process, the material removal mode caused by different grits is different due to the different positions and protrusion heights of the grits. During ductile-mode cutting, material removal is realized by the plastic flow of the workpiece, while in brittle mode, material removal is dominated by brittle fracture. The machined surface also undergoes elastic recovery. Therefore, it is necessary to consider the elastoplastic deformation of the workpiece surface when modelling ground surface roughness. Muhammad et al. [38] proposed that all brittle materials experience a brittleductile transition. When the undeformed chip thickness is lower than this threshold, plastic deformation becomes energetically favorable. Building on this work, Jiang et al. [39] developed a model to describe the machined surface profile based on the material removal mechanism of optical glass, and found that the brittle material removal fraction influences the surface roughness. Li et al. [40] proposed a model of ground surface 
topography considering the ductile-regime effect in the monocrystalline silicon grinding. This model not only described the proportion of brittle and ductile regions but also accurately predicted the machined surface roughness. Microscopic simulation is considered the most detailed approach to simulate grinding. However, as the scale of machining shrinks to sub-micrometer dimensions, the undulations in the machined topography start to overlap with the extent of elastic recovery of the workpiece, posing challenges in the accurate estimation of material's elastic recovery. In a recent work $[41,42]$, the authors of this paper proposed a novel method to quantify the elastic recovery of silicon during ultra-fine rotational grinding. Experimental results showed that this method will reliably estimate the elastic recovery and the tip radius of active grits.

\subsection{Analytical models based on machining theory}

In addition to the numerical models discussed above, many scholars have also attempted to predict the ground surface roughness by using analytical models. Analytical models, especially the undeformed chip-thickness model, usually have simplified assumptions in comparison to the numerical models and have played an important role in improving predictions of ground surface roughness. The chipthickness models proposed by Reichenbach et al. [43] were based on the ratio of the wheel speed to the work speed, depth of cut and equivalent diameter of the grinding wheel to describe the grinding process. Soneys et al. [44] simulated the grinding process by considering chip thickness, grinding force and surface roughness. They proposed a relationship between the equivalent chip thickness and surface roughness. These studies assume that the relationship between equivalent chip thickness and grinding force, surface roughness and metal removal rate is linear. Additionally, these models only focus on the effect of grinding parameters and do not consider the parameters related to the topography of the grinding wheel. Unlike the equivalent chip thickness models, the maximum undeformed chip thickness $\left(h_{\max }\right)$ based models consider the effect of grinding parameters as well as the parameters related to the grinding wheel topography. 
Therefore, these models have been more widely used in studies describing the process of ground surface roughness. Some of the most popular representative models available to calculate $h_{\max }$ and the assumptions underneath are listed in Table 1.

Table 1 Models related to undeformed chip thickness and basic assumptions.

\begin{tabular}{|c|c|c|}
\hline Researchers & Formulas & Basic assumptions \\
\hline $\begin{array}{l}\text { Pahlitzsch } \\
\text { et al. [46] }\end{array}$ & \multirow{2}{*}{$h_{m}=2 L\left(\frac{v_{w}}{v_{s}}\right)\left(\frac{a_{e}}{d_{e}}\right)^{1 / 2}$} & \multirow{2}{*}{$\begin{array}{l}\text { (i) The abrasive grits have the same radial } \\
\text { distance and equal spacing. }\end{array}$} \\
\hline $\begin{array}{c}\text { Basuray et } \\
\text { al. [50] }\end{array}$ & & \\
\hline $\begin{array}{l}\text { Malkin et } \\
\text { al. [48] }\end{array}$ & $h_{m}=\left[\frac{4}{C r}\left(\frac{v_{w}}{v_{s}}\right)\left(\frac{a_{e}}{d_{e}}\right)^{1 / 2}\right]^{1 / 2}, \quad C=\frac{1}{L B}$ & $\begin{array}{l}\text { (i) The shape of the grits is spherical and } \\
\text { shares the same size. } \\
\text { (ii) The locations of all the grits follow } \\
\text { uniform distribution and the protrusion } \\
\text { heights are the same }\end{array}$ \\
\hline $\begin{array}{l}\text { Malkin et } \\
\text { al. [48] }\end{array}$ & $h_{m}=2 L\left(\frac{v_{w}}{v_{s}}\right)\left(\frac{a_{e}}{d_{e}}\right)^{1 / 2}-\delta_{\mathrm{n}}$ & $\begin{array}{l}\text { (i) Stationary wheel. } \\
\text { (ii) Neatly arranged abrasive grits on the } \\
\text { wheel. }\end{array}$ \\
\hline $\begin{array}{l}\text { Huang et al. } \\
\text { [45] }\end{array}$ & $h_{m}=\left(\frac{3}{C \tan \theta}\right)^{0.5}\left(\frac{v_{w}}{v_{s}}\right)^{0.5}\left(\frac{a_{e}}{d_{e}}\right)^{0.25}$ & $\begin{array}{l}\text { (i) Abrasive grits follow uniform } \\
\text { distribution. } \\
\text { (ii) The shape of the abrasive grits is a } \\
\text { sphere and the profile generated by the grit } \\
\text { is a circular arc. }\end{array}$ \\
\hline $\begin{array}{l}\text { Darafon et } \\
\text { al. [53] }\end{array}$ & $h_{m}=2 L\left(\frac{v_{w}}{v_{s}}\right)\left(\frac{a_{e}}{d_{e}}\right)^{1 / 2}$ & $\begin{array}{l}\text { (i) The shape of the abrasive grit is a sphere } \\
\text { and the profile generated by the grit is a } \\
\text { circular arc. } \\
\text { (ii) Abrasive grit height is normally } \\
\text { distributed }\end{array}$ \\
\hline $\begin{array}{c}\text { Ding et al. } \\
\text { [63] }\end{array}$ & $h_{m}=2 L \frac{v_{w}}{v_{s}}\left(\frac{a_{j-1}}{d_{s}}\right)^{1 / 2}-2 \frac{v_{w}}{v_{s}}\left(1+\frac{v_{w}}{v_{s}}\right)\left[a_{j-1}-\left(a_{j} a_{j-1}\right)^{1 / 2}\right.$ & $\begin{array}{l}\text { (i) The size of the abrasive grits is normally } \\
\text { distributed, and the positions are randomly } \\
\text { distributed. }\end{array}$ \\
\hline $\begin{array}{l}\text { Hecker et } \\
\text { al. [56] }\end{array}$ & $f\left(h_{\max }\right)= \begin{cases}\left(h_{\max } / \sigma^{2}\right) e^{-h_{\max }^{2}} / 2 \sigma^{2} & h_{\max } \geq 0 \\
0 & h_{\max }<0\end{cases}$ & $\begin{array}{l}\text { (i) The shape of the abrasive grits is conical. } \\
\text { (ii) The undeformed chip thickness follows } \\
\text { the Rayleigh distribution. }\end{array}$ \\
\hline
\end{tabular}

Huang et al. [45] studied high-speed grinding of silicon nitride when using resin bonded diamond wheels. They analysed the effects of wheel speed, depth of cut and workpiece feed rate on surface roughness and developed a functional relationship between surface roughness and maximum undeformed chip thickness (see Fig. 9). They pointed out that the ground surface roughness during the brittle-mode grinding process is not significantly affected by $h_{\max }$. However, when $h_{\max }$ exceeds a certain critical value, the fracture grows to a larger length scale, for example, from micro-fracture to large grit dislodgement. Therefore, the value of surface roughness increases. This research showed that for a given combination of abrasive grits and workpiece material, there exists an optimal value of undeformed chip thickness. Better workpiece surface 
finishing can be obtained by controlling the undeformed chip thickness of all abrasive grits within a small range.

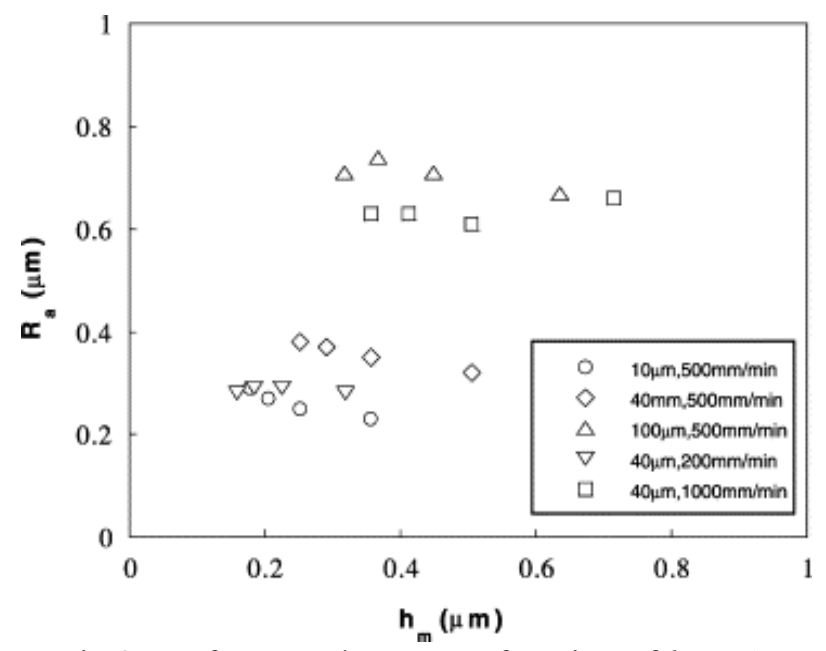

Fig.9. Surface roughness as a function of $h_{\mathrm{m}}$ [35].

\subsubsection{The assumption of uniform probability distribution of abrasive grits}

According to Huang et al. [45], better workpiece surface finishing can be achieved by determining an optimal value of the undeformed cutting thickness. The undeformed chip thickness can be theoretically determined by the topological structure of the grinding wheel and the process parameters. Researchers have attempted to develop various undeformed chip thickness based models. Pahlitzsch [46] used the distance between adjacent grits to describe the topography of the grinding wheel and developed a model of the maximum undeformed chip thickness as:

$$
h_{m}=2 L\left(\frac{v_{w}}{v_{s}}\right)\left(\frac{a_{e}}{d_{e}}\right)^{1 / 2}
$$

where $L$ is the lateral distance between two adjacent grits. As it is difficult to determine the value of $L$, Shaw and Reichenbach [47] improved Pahlitzsch's model by calculating the average volume of the cutting layer based on the number of active abrasive grits. Malkin et al. [48] proposed a new model to calculate the maximum undeformed chip thickness $h_{\max }$ by using the grinding grit density $\mathrm{C}$ (number of abrasive grits per unit area) and $r$ (chip width-to-thickness ratio) as:

$$
h_{m}=\left[\frac{4}{C r}\left(\frac{v_{w}}{v_{s}}\right)\left(\frac{a_{e}}{d_{e}}\right)^{1 / 2}\right]^{1 / 2}, \quad C=\frac{1}{L B}
$$

where $L$ and $B$ are the lateral and longitudinal distances between two adjacent abrasive 
grits, respectively and $r$ is the width-to-thickness ratio.

These models were based on the following two assumptions:

(i) The abrasive grits are all spherical and of the same size;

(ii) The grits follow a uniform distribution and have the same protrusion heights. These assumptions do not truly reflect the stochastic nature of the distribution of grits. Quantitative detailing of the grit-workpiece interactions is important for gaining a deeper understanding of the grinding process. However, due to the randomness of the shape, position and size distribution of the abrasive grits, the interactions between the abrasive grits and the workpiece are difficult to be determined experimentally and described analytically. Tonshoff et al. [12] proposed a general chip thickness model by comparing multiple chip thickness models including one, two and three-dimensional descriptions of the wheel surface. In their model, they considered the parameters related to the motion and the geometric parameters and used topography to explore the structure of the grinding wheel and describe the chip formation. However, they did not consider the deformation of the grinding contact zone, which may significantly increase the number of cutting edges in contact with the workpiece, resulting in smaller chip thickness. Brown et al. [49] focused on the deformation of the grinding contact zone and divided the elastic deformation of the grinding contact zone into two parts:

(i) The deformation of the wheel and the workpiece and

(ii) The deformation between the active abrasive grits and the workpiece.

In addition, they validated the effect of elastic deformation of the contact zone on the chip thickness model by developing a contact length model using Hertz theory. The above models predicting the maximum undeformed chip thickness are based on the consideration of single grits, and analyse the grit path and the grit-workpiece interactions. These models also continue to assume that the abrasive grits are uniformly distributed on the surface of the grinding wheel. This assumption means that all abrasive grits in the grinding wheel-workpiece contact zone would be involved in chip formation and have the same chip thickness. Indeed, all the above models for maximum undeformed chip thickness $h_{\max }$ are based on the average distance between abrasive grits and their average height, and the nonuniformity of abrasive grits, which may 
adversely affect the prediction accuracy of surface roughness, is not considered.

\subsubsection{Consideration of the stochastic nature of abrasive grits}

During the grinding process, randomly distributed abrasive grits (different shapes, sizes, protrusion heights, and positions) come in contact with the workpiece material leading to stochastic changes in the undeformed chip. Based on the previous model (Eq.2), Malkin [48] developed an undeformed chip thickness model considering the difference in height between the adjacent grits:

$$
h_{m}=2 L_{n}\left(\frac{v_{w}}{v_{s}}\right)\left(\frac{a_{e}}{d_{e}}\right)^{1 / 2}-\delta_{\mathrm{n}}
$$

where $\delta_{\mathrm{n}}$ is the undeformed chip thickness produced by the difference in height between the adjacent grits. This model was developed under the condition of a stationary wheel, so it is suitable for describing a structure with abrasive grits having regular periodicity (such as milling) but not for randomly distributed abrasive grits. Basuray et al. [50] evaluated the surface roughness during fine grinding by developing a simple model. They obtained the distribution of grits on the wheel surface by using the concept of radial distribution parameter and effective profile depth associated with the stochastic model. However, in their work, many parameters and material properties were regarded as empirical constants. Zhou and $\mathrm{Xi}$ [51] considered random distribution of the grit protrusion heights and proposed a systematic search method for the surface profile from the highest protruded grit in descending order. Hou [52] assumed that the diameter of grits is normally distributed and used only one variable to express both the grit size and the grit protrusion, where the biggest grit represents the highest protrusion while the smallest grit has the lowest protrusion. Fig. 10a shows the maximum and minimum diameter of the grits and the probability distribution of other grains. Fig. 10b sheds light on the normal distribution plot of the frequency versus the grit diameter. 


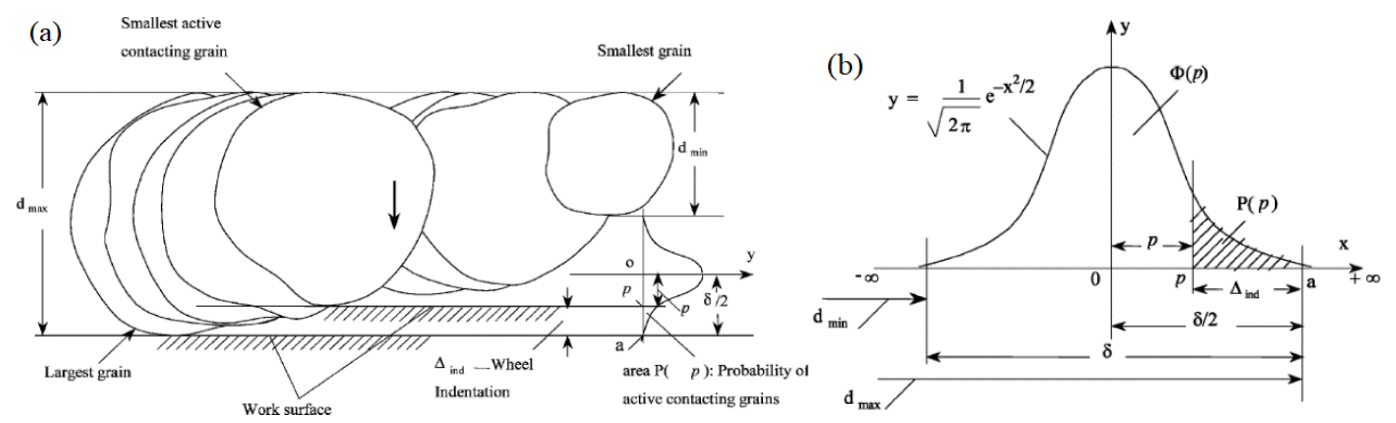

Fig. 10. (a) Schematic of the grit size distribution showing maximum and minimum diameters of the grits and the probability distribution of other sizes of the grits and (b) normal distribution plot of the frequency versus the grit diameter [52].

The assumption of normal distribution in the size and protrusion does not accurately represent an actual grinding process, considering that the abrasive grits are randomly distributed inside the grinding wheel, and the size and protrusion height of the abrasive grits are independent of each other. Darafon et al. [53] proposed a new roughness model by assuming the shape of the abrasive grits to be spherical, as shown in Fig. 11a. Metal removal achieved by the sphere with the line segments at discrete time intervals (vertical dashed lines in Fig. 11a. Fig. 11b) shows the simulated chip model which can be used to determine the thickness of the undeformed chip, the contact length and surface roughness without requiring any parameter adjustment. However, the calculations done by this method are time-consuming and the distribution of undeformed chip thicknesses cannot be analyzed. Jiang et al. [54] assumed normally distributed grit size and randomly distributed grit locations. They divided the grits into four types: non-contact, sliding, ploughing and cutting grits in a redefined 'grinding contact zone'. The undeformed chip thickness $\left(h_{\max }\right)$ and the number and distribution of different types of abrasive grits were obtained by analyzing the interactions of different types of abrasive grits and the workpiece in the grinding contact zone which can be used for more precise calculations for ground surface roughness prediction. This work improved upon the calculation efficiency of Darafon et al. [53] by classifying the abrasive grits in the grinding contact zone. However, this model did not extract and analyze the distribution characteristics of the undeformed chip thickness. 


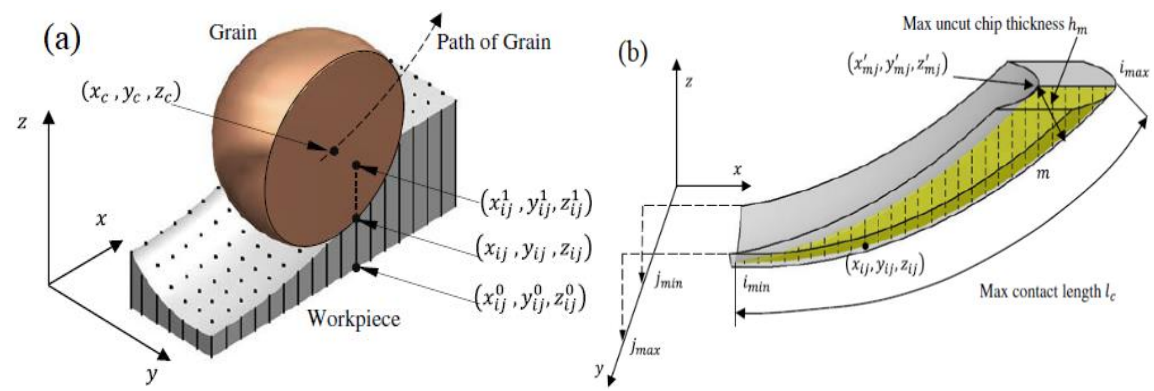

Fig. 11. 3D simulation model in Darafon's work (a) Metal removal simulation for a single grit and (b) the undeformed chip thickness and contact length on the 3D chip [53] .

\subsubsection{Consideration of the non-uniformity of abrasive grits and extraction of} distribution of undeformed chip thickness

The spatial distribution of abrasive grits on the grinding wheel determines the distribution of the undeformed chip thickness which affects the chip formation and the interaction between the wheel and the workpiece. In order to fully analyse this problem, many researchers began to consider the randomness of the grinding process by developing analytical models based on probability distributions. Younis and Alawi [55] developed an undeformed chip thickness model based on Rayleigh's probability density function, and this model has been widely used in subsequent research. Hecker et al. [56] assumed that each groove had a triangular shape (Fig. 12a) that comes from the projection of the conical shape for the active grits, and the probability distribution of undeformed chip thickness follows a Rayleigh distribution as in Fig. 12b, which shows that the material will be removed as a chip for those depths of engagement greater than the critical depth of cut, $h_{\mathrm{cr}}$. Based on this, the authors expressed surface roughness as a function of the wheel microstructure, the process kinematic conditions and workpiece material properties, and developed a surface roughness prediction model based on the thickness of undeformed chips.
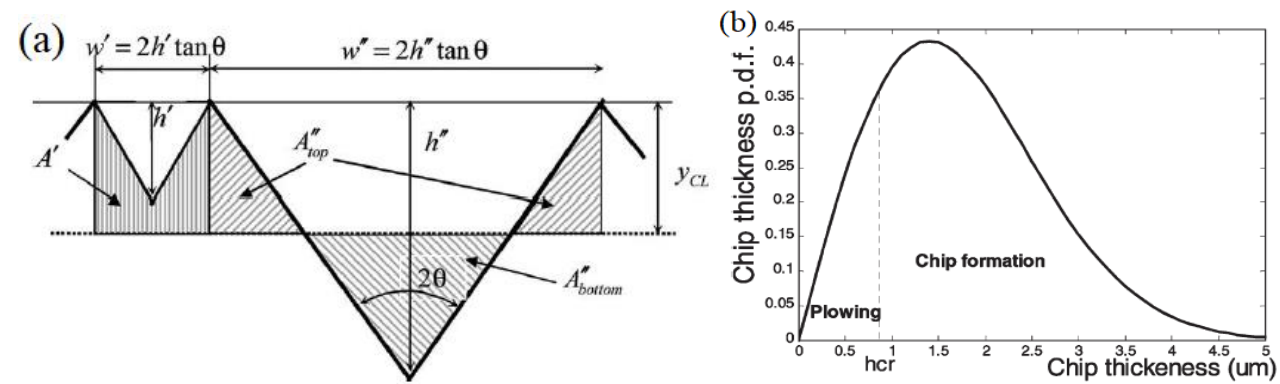

Fig. 12. Assumptions in Hecker's work. (a) Theoretical profile generated by grit grooves and (b) 
Chip thickness probability density function [56].

In the work of Hecker et al. [56], the shape of abrasive grits was assumed to be conical, and a single abrasive grit was assumed to produce a triangular groove. This assumption neglected the fact that the geometry of the tiny abrasive cutting edges on the grinding wheel surface during grinding is stochastic. Lal et al. [57] conducted experiments on a single abrasive grit under fine grinding conditions and modelled the tip of the abrasive grits using the arc method. They proposed that the grooves generated by a single abrasive grit can be approximated by a circular arc. Based on this assumption, Agarwal et al. $[58,59]$ approximated the grooves produced by a single abrasive grit on the surface of the workpiece with a circular arc and proposed a new analytical surface roughness model by assuming the profile generated by the grit as shown in Fig. 13a. In their method, the relationship between surface roughness and the chip thickness was developed with the chip thickness as a random variable. However, in their later work [60], they assumed that the grooves generated by a single abrasive grit are parabolic and the paraboloid profile generated by the grit is shown in Fig. 13b. The authors developed a new analytical model to predict the surface roughness. In addition to the wheel's microstructure, kinematic and dynamic grinding conditions and material properties were also included in the model. They also considered the overlapping effect of grooves left by the grits.

(a)

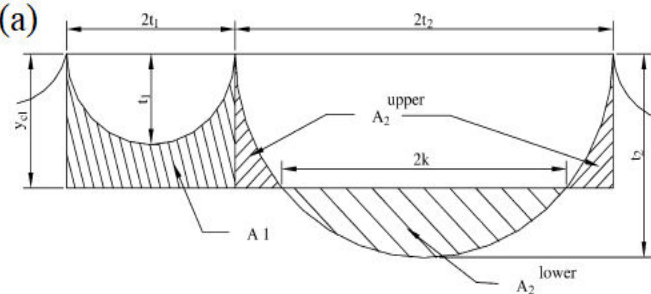

(b)

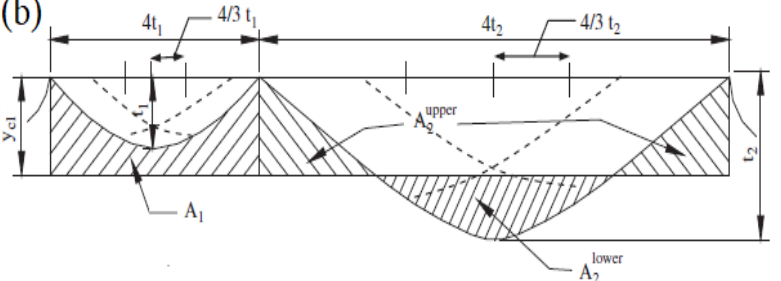

Fig. 13. Shape of the profile generated by grit grooves is (a) circular arc $[58,59]$ and (b) paraboloid [60].

In the above studies, the undeformed chip thickness models developed were based on the geometric contact length alone or the contact length obtained due to the combined effect of deflection caused by the grinding wheel-workpiece contact and the geometric grinding contact zone without considering the wheel and the workpiece elastic deformation caused by contact. However, during the grinding process, the elastic 
characteristics of the grinding wheel and the workpiece inelastically deform the material in the contact zone leading to an increased contact length. Thus, the real contact length is longer than the theoretically estimated contact length. Therefore, a model that is based on the geometric contact length does not correctly consider the influence of the undeformed chip thickness. Based on this, Agarwal et al. [61] improved their own model. Their new model was developed on the basis of the real contact length that results from combined contact length due to (a) the wheel-workpiece contact zone deflection and the local deflection due to the microscopic contact at the grit level, and (b) contact length due to geometry of depth of cut. Compared to the undeformed chip thickness model, this model can predict surface roughness more accurately. Khare et al. [62] assumed that the undeformed chip thickness follows the Rayleigh distribution and developed an analytical model on the basis of the probability density function of the undeformed chip thickness. This model was mainly determined by the random geometry and random distribution of the cutting edges and was validated by the experimental results of AISI 4340 steel in surface grinding.
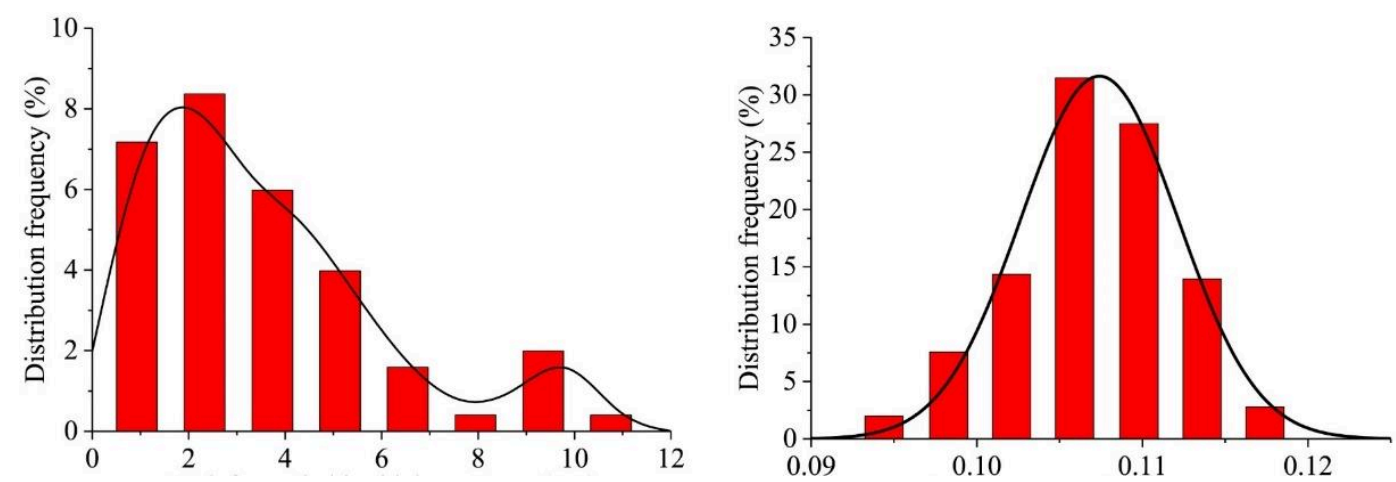

Fig. 14. Results of undeformed chip thickness from (a) Malkin's model and (b) Improved model proposed by Ding et al. [63]

Most of these analytical models were developed under the assumption that the undeformed chip thickness follows the Rayleigh distribution while some used the assumption of normal distribution. Based on Malkin's model (Eq.3), Ding et al. [63] developed the maximum undeformed chip thickness model of the CBN grinding wheel by using the Johnson transformation and its inverse transformation which was highlighted earlier in Table 1 . In their work, the influence of the non-uniformity of undeformed chip thickness on the surface roughness was considered and compared with 
the model of Malkin. A comparison of the two models is shown in Fig. 14 and indicates that the model developed in the latter work can better express the non-uniformity of the undeformed chip thickness. Moreover, Fig. 14b suggests that the undeformed chip thickness of the $\mathrm{CBN}$ wheel tends to follow a normal distribution rather than a Rayleigh distribution. Zhang et al. [64] combined the parameters related to the workpiece, kinematics and single-grit undeformed chip thickness and proposed a model for calculating surface topography of the grinding wheel to obtain the undeformed chip thickness distribution. In this model, the distributed randomness of abrasive grits and the influence of mutual interference (overlapping) of grits was considered. As shown in Fig. 15a, the topography of a region on the grinding wheel surface was obtained by using laser confocal microscopy. After measuring the protrusion heights of all grits in eight different regions, the statistical distribution of the grit protrusion heights shown in Fig. 15b was obtained, revealing a normal distribution. The authors also proposed that the protrusion height of the abrasive grits is about $3 / 4^{\text {th }}$ of the entire abrasive grit size, so the grit size distribution can be obtained as shown in Fig. 15b. The authors used a wheel topography model to simulate the grinding process and found that the characteristics of the undeformed chip thickness distribution will change with the variation in the radial dressed height (Fig. 16a). Fig. 16b shows that an increase in the radial dressing height decreases the mean value of undeformed chip thickness. Additionally, they also determined the relationship between the mean value of undeformed chip thickness distribution and surface roughness via simulation based on the integrated model of the undeformed chip thickness distribution (Fig. 17). The authors concluded that the mean value of the surface roughness can be controlled quantitatively by radial numerical dressings on the wheel. 

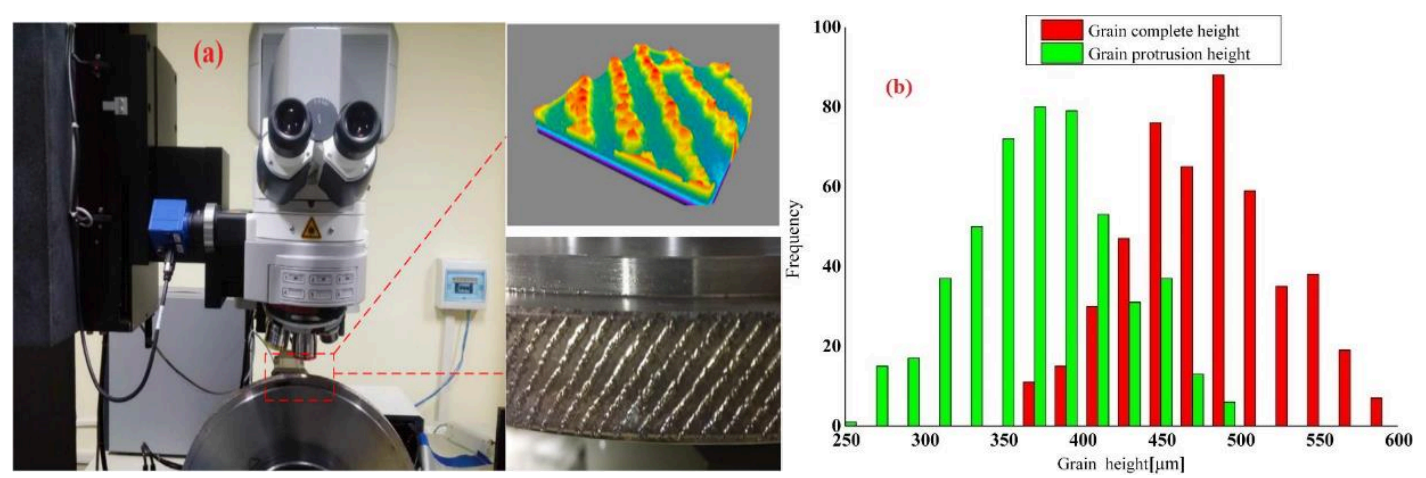

Fig. 15. Measuring method and result of grinding wheel topography. (a) 3D topography of wheel as measured with laser confocal microscopy and (b) Measured distribution of the grit size and protrusion height [64].
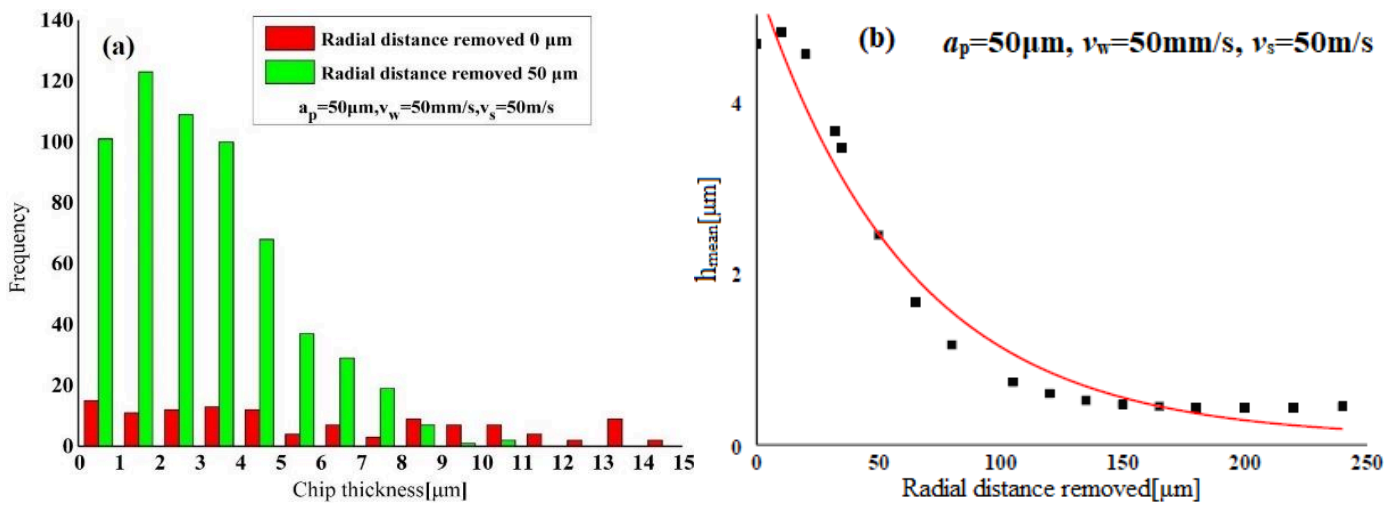

Fig. 16. Relationship between the radial dressed height and undeformed chip thickness. (a) Distribution of undeformed chip thickness at different radial numerical dressing states and (b) Change average value of the undeformed chip thickness with the radial dressed height of the grinding wheel [64].
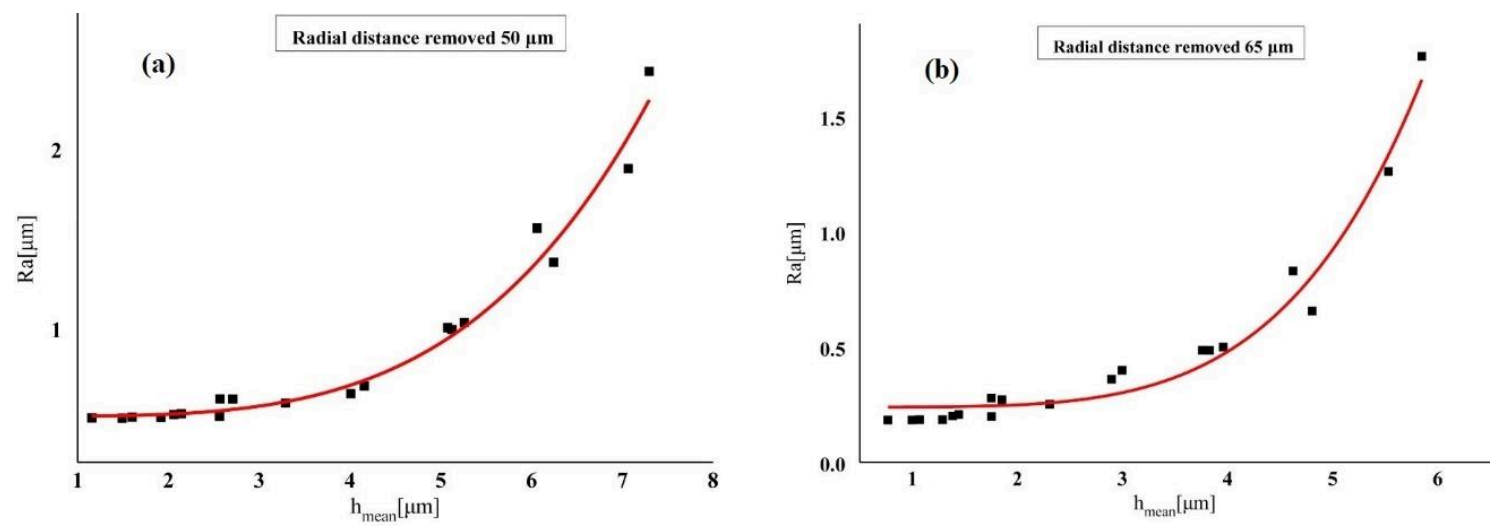

Fig. 17. Relationship between the average value of the undeformed chip thickness distribution and Ra. (a) Radial distance removed 50 $\mu \mathrm{m}$ and (b) Radial distance removed $65 \mu \mathrm{m}$ [64].

\subsection{Remarks}

A careful review of the models in papers discussed in the above section leads to the conclusion that theoretical studies predict ground surface roughness in terms of kinematics and geometry by describing material removal and the formation mechanism. 
These models provide deeper knowledge about the grinding process. However, there are some simplified assumptions in these studies which omit certain practical aspects of the grinding process. In what follows, we expand on these:

(i) Assumptions related to the material removal process: Material removal during grinding can be divided into two forms: brittle-mode (fracture dominated) and ductilemode (plastic deformation dominated). During plastic deformation, elastic recovery of the material is more pronounced whereas brittle mode machining largely depends on the stochastic distribution of the grits (leading to uncertain cutting depths presented by each grit). These complex mechanisms make it difficult to determine the material removal process under the action of single grit scratch. Specifically, when the expected machining dimensions approach sub-micron levels, these considerations are an important factor.

(ii) Assumptions related to the shape and distribution of the abrasive grits: The shape and the protrusion heights of the grits are important factors affecting the surface topography of the ground part. Due to the need for the analytical derivation or numerical computation, analytical models are developed with a range of assumptions to simplify the modelling process. As a result of this, the accuracy and applicability of the analytical models are limited. Also, the numerical simulation models are generally based on the actual measurement of the surface topography of the grinding wheel. However, the cost of measurement is high and the accuracy is always in question. Moreover, the wear and tear of the abrasive grits on the surface of the grinding wheel are affected by the force on the grits during the grinding process. In other words, the process parameters will affect the shape and distribution of the abrasive grits. Therefore, it is difficult to describe the shape and distribution of abrasive grits.

(iii) Assumptions related to the process parameters: Most of the current models still focus on the grinding process and do not consider the experimental variability arising from chatter, vibration and loop stiffness of the machine tool. The grinding machine is assumed to be ideally stiff. In precision grinding, these factors can significantly influence the grinding outcomes. Future work is necessary to investigate this issue.

(iv) Assumptions related to the roughness formation mechanism: The existing 
models do not consider secondary factors that contribute to the roughness formation mechanism, for example, wear and deflection of the cutting tool and thermal issues (grinding process heat and heat generated from the moving parts). In the actual grinding process, some large grits may be forced to penetrate deeply into the workpiece, resulting in significantly high force and tool wear. As a result, the ground surface could be affected, and subsurface damage could occur due to overheating. The integration of these factors to the current models is estimated to increase their accuracy, especially in cases of finishing procedures where their influence is large.

Overall, due to the complexity of the grinding process, it is still difficult to accurately predict surface roughness by these models. Additionally, considering that we will need to deal with an array of the diversified materials in future, developing a simulation or analysis model for each material would be difficult and time-consuming. However, these models approximately describe the relationship between the parameters of the grinding process and the surface roughness, like Malkin's model (Eq. (2)) is widely adopted in the grinding mechanism research and process optimization. Also, models based on machining theory can reveal the principle of material removal and surface formation mechanism. In the future, these models can be employed in conjunction with data-driven models.

\section{Methods based on experimental design and analysis}

The experimental design and analysis methods base their predictions on the design of experiments, data processing and analysis. Regression analysis, Quantile Regressions, Response Surface methodology and Taguchi methods for the design of experiments (DoE) are the most wide-spread methodologies for predicting surface roughness.

\subsection{Regression methods}

In the regression analysis method, experimental data is used to establish the regression function between the independent variable and the dependent variable(s) in the research model, which is called the regression equation $[65,66]$. The application principle of a simple regression analysis method in the prediction of grinding roughness 
is to take the grinding parameter as the independent variable and the roughness as the dependent variable, use experimental data to establish a regression equation between these two variables, and then predict the roughness by using the regression equation. For example, one may evaluate a simple regression equation as follows:

$$
R_{a}=c+\beta_{1} a_{e}+\varepsilon_{i}
$$

where $R_{\mathrm{a}}$ denotes the roughness and $a_{e}$ the grinding depth. Eq. (4) defines a straight line. The parameter $c$ is the constant or intercept, and $\varepsilon_{i}$ represents the error of this model estimation. The parameter $\beta_{1}$ represents the expected increment in the response $R_{\mathrm{a}}$ per unit change in $a_{e}$. The linear model in Eq. (4) assumes that the included regressor $\left(a_{e}\right)$ is the only determinant of surface roughness, and the model solution (done usually via ordinary least squares) assumes that the error $\varepsilon_{i}$ is normally distributed and not related to the regressor.

An improvement in the simple regression model is to have multiple independent or explanatory variables (regressors) and conduct multiple regression modeling. Multiple regression analysis can help in identifying several models that can be used for predicting surface roughness and one can choose the model that can explain the maximum variation in the experimental data. For example, Eq. (4) can be extended as follows:

$$
R_{a}=c+\beta_{1} a_{e}+\beta_{2} v_{w}+\beta_{3} v_{s}+\beta_{4} d_{e}+\varepsilon_{i}
$$

where $a_{e}$ is the grinding depth, $v_{w}$ is the workpiece infeed speed, $v_{s}$ is the wheel speed, and $d_{e}$ is the diameter of the wheel. The parameters $\beta_{1}, \beta_{2}, \beta_{3}$ and $\beta_{4}$ represent the expected increment in the response $R a$ per unit change in $a_{e}, v_{w}, v_{s}$ and $d_{e}$ respectively.

The main idea behind regression models is to describe the mean of the response variable for each fixed value of the regressors using the conditional mean of the response. A further improvement is to apply the Quantile Regression technique[65,66], which fits regression curves to other parts of the distribution of the response variable (and not merely the mean). While multiple regressions provide a summary for the means of the distributions corresponding to the set of regressors, Quantile regression helps to compute several different regression curves corresponding to the various 
percentage points of the distributions and thus provides a more complete picture of the data. The $\tau^{\text {th }}$ quantile could be thought of as splitting the area under the probability density into two parts: one with the area below the $\tau^{\text {th }}$ quantile and the other with area $1-\tau$ above it. For example, $10 \%$ of the population lies below the $10^{\text {th }}$ quantile. Thus, Eq. (5) for the $\tau^{\text {th }}$ quantile will transform to the following equation:

$$
R_{a}=c+\beta_{1} a_{e}^{\tau}+\beta_{2} v_{w}^{\tau}+\beta_{3} v_{s}^{\tau}+\beta_{4} d_{e}^{\tau}+\varepsilon_{i}
$$

While the Multiple Regression Model (Eq. (5)) specifies the change in the conditional mean of the dependent variable (surface roughness) associated with a change in the regressors, the Quantile Regression Model (Eq. (6)) specifies changes in the conditional quantile. Thus, the Quantile Regression model can be considered a natural extension of the Multiple Regression model. This model can help in inspecting the rate of change of surface roughness by quantiles. Thus, while (Eq. (5)) addresses the question "how do grinding depth, workpiece infeed speed, wheel speed, and diameter of wheel affect surface roughness?", it does not and cannot answer a more nuanced question: "Do grinding depth, workpiece infeed speed, wheel speed, and diameter of wheel influence surface roughness differently for samples with low surface roughness than for samples with average surface roughness?" The latter question can be answered by (for example) comparing the regression for the $50^{\text {th }}$ quantile with that for the $10^{\text {th }}$ quantile of surface roughness [65]. The regression model of grinding surface roughness prediction is listed in Table 2. The quantile regression of grinding leading to healthy predictions is still an open research question.

Table 2 Literature review on regression model of grinding surface roughness.

\begin{tabular}{|c|c|c|c|}
\hline $\begin{array}{l}\text { AISI D3 Tool } \\
\text { steel [67] }\end{array}$ & $\begin{array}{c}\text { Alumina } \\
\text { grinding } \\
\text { wheel } \\
\end{array}$ & $R_{a}=v_{w}^{-0.138} 0.121 v_{s}^{0.000305} \beta_{4} d_{e}^{-0.475}$ & $\begin{array}{l}\text { Feed velocity }\left(v_{\mathrm{w}}\right), \\
\text { cutting speed }\left(v_{\mathrm{s}}\right), \\
\text { depth of cut }\left(d_{\mathrm{e}}\right)\end{array}$ \\
\hline $\begin{array}{l}\text { Modern } \\
\text { ceramic [68] }\end{array}$ & $\begin{array}{c}\mathrm{SiC} \\
\text { grinding } \\
\text { wheel } \\
\end{array}$ & $R_{a}=0.21+11.17 d_{e}+0.04 v_{w}-0.002 w_{s}$ & $\begin{array}{c}\text { Depth of cut }\left(d_{\mathrm{e}}\right), \\
\text { Feed velocity }\left(v_{\mathrm{w}}\right), \\
\text { Grit Size }(w)\end{array}$ \\
\hline $\begin{array}{l}\text { AISI D2 steel } \\
{[69]}\end{array}$ & $\begin{array}{l}\text { Corundum } \\
\text { grinding } \\
\text { wheel }\end{array}$ & $R_{a}=8.831+3.78 d_{e}-0.205 w-0.6 d_{e}^{2}+0.00112 w^{2}$ & $\begin{array}{l}\text { Depth of cut }\left(d_{\mathrm{e}}\right), \\
\text { Grit Size }(w)\end{array}$ \\
\hline \multirow{2}{*}{$\begin{array}{c}\text { Inconel } \\
\text { superalloy } \\
{[70]}\end{array}$} & \multirow{2}{*}{$\mathrm{CBN}$} & $R_{a}=0.14+0.0207 d_{e}+0.0013 v_{w}-0.00036 d_{e}^{2}$ & \multirow{2}{*}{$\begin{array}{l}\text { Depth of cut }\left(d_{\mathrm{e}}\right), \\
\text { feed velocity }\left(v_{\mathrm{w}}\right), \\
\text { nanoparticles } \\
\text { concentration }(n)\end{array}$} \\
\hline & & $R_{a}=0.138+0.0097 d_{e}+0.0015 v_{w}-0.004 n+0.000022 n^{2}$ & \\
\hline
\end{tabular}




\subsection{Response Surface Methodology}

Response Surface Methodology (RSM) is a combination of mathematical and statistical techniques for optimizing the process parameters to achieve the desired output [71]. In this method, a multivariate quadratic regression equation is used to fit the functional relationship between the test index and the response value and then the optimal process parameters can be obtained by the fitted regression equation. The function that consists of the process parameters is called a response surface (see Fig. 18). The design procedure of RSM is as follows [72]:

(i) experimental design;

(ii) developing a mathematical model of the second-order response surface with best fittings;

(iii) finding the optimal set of experimental parameters that produce a maximum or minimum value of response;

(iv) representing the direct and interactive effects of process parameters through two- and three-dimensional plots [73].

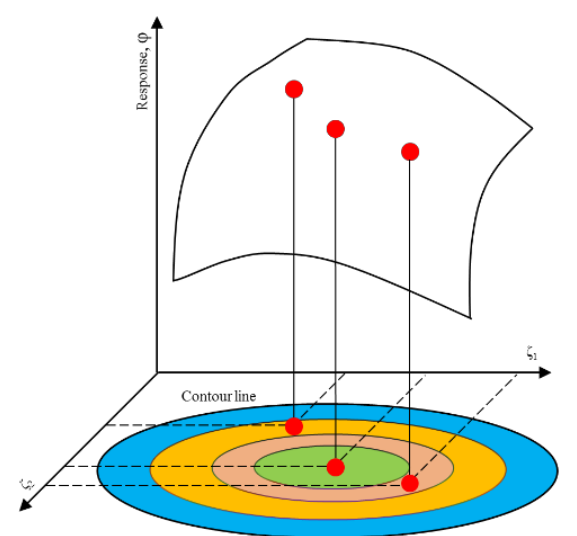

Fig. 18. Response surface model [74].

The application principle of RSM in the prediction of grinding induced roughness is to take the grinding parameter as the process variable and roughness as the response value and fit the functional relationship between the process variable and the response value by using the multiple quadratic regression equation to predict surface roughness. Kwak et al. $[74,75]$ developed the RSM models to predict grinding power and surface roughness in the external cylindrical grinding of hardened SCM440 steel. They measured and evaluated the surface roughness according to the change of the grinding 
conditions (workpiece speed, depth of cut, and the traverse speeds) and predicted the grinding power and the surface roughness by developing the response surface models as per Eqs. (7) and (8).

$$
\begin{aligned}
P_{0}= & 359.83797-0.10070 v^{2}-184.65033 f^{2} \\
& -0.65 d^{2}+3.95418 v f+0.45254 v d \\
& +24.94593 f d \\
R_{a} & =0.21369-0.00009 v^{2}-0.09995 f^{2} \\
& +0.00051 d^{2}+0.01156 v f+0.00002 v d \\
& -0.00979 f d
\end{aligned}
$$

Mohanasundararaju et al. [76] developed a surface roughness prediction model for D2 steel grinding of work rolls by using RSM. Six grinding parameters namely, the wheel speed, workpiece speed, traverse speed, in-feed, dress depth, and dressing lead were considered in the experiments and the optimal process parameters were determined by non-linear programming and genetic algorithm. In their work, the analysis of variance (ANOVA) showed that the most significant grinding parameter affecting the surface roughness is the speed of the grinding wheel followed by the traverse speed and the in-feed. The effect of the dressing depth on the surface roughness of the work roll was greater than that of the dressing lead and work speed. Neşel et al. [77] studied the effects of workpiece revolution, feed rate and depth of cut on vibrations and surface roughness in cylindrical grinding. They measured the changes of grinding wheel vibration and surface roughness based on the signal-to-noise $(\mathrm{S} / \mathrm{N})$ ratio using the Taguchi method [77] and developed the objective function by RSM, and then obtained the optimal process conditions by computer-aided single-objective optimisation. Their experimental and statistical results showed that the workpiece revolution has a more significant effect on the surface roughness and vibrations during cylindrical grinding followed by the depth of cut. To improve the surface quality of integrally bladed rotors, Zhao et al. [78] performed the experiments with four input parameters: abrasive size, contact force, belt linear velocity and feed rate. They determined the optimal range of each factor by single factor experiment and developed a prediction model of surface roughness based on central composite design experiments 
and quadratic regression. The optimum process parameters were obtained by comparing the $\mathrm{S} / \mathrm{N}$ ratio and RSM. The experimental results showed that compared to the SNR method, RSM revealed better surface quality. Rudrapati et al. [79] investigated the effect of machining parameters on the surface roughness in traverse cut cylindrical grinding of stainless steel material. Three grinding parameters namely, infeed, longitudinal feed and workpiece speed were selected as the input parameters to investigate the relationship between the grinding parameters and the output response using RSM. The ANOVA of surface roughness showed that the infeed, squared combinations of both longitudinal feed and work speed, and interaction effects of infeed*longitudinal feed and longitudinal feed*work speed have a significant effect on the surface roughness while the individual effect of work speed has an insignificant effect on surface roughness. To achieve the surface roughness requirements in the multipass roller grinding process, Chen et al. [80] proposed an optimization method with a hybrid particle swarm optimization based on the RSM of the surface roughness. In this method, the hybrid particle swarm optimization regarded the entire grinding process parameters as a whole and optimized the grinding parameters by considering multiple objectives and constraints. The surface roughness of different processing stages based on the optimal parameters is shown in Fig. 19a. In Fig.19a, (0-2) is the rough grinding stage; (3-5) is the process of semi-fine grinding; (6-7) is the stage of finish grinding; (8-9) is the spark-out grinding. Fig. $19 \mathrm{~b}$ is the evolution of the predicted surface roughness, which shows the initial and final roughness as $0.54 \mu \mathrm{m}$ and $0.276 \mu \mathrm{m}$ respectively, and the maximum error of around $16.53 \%$.
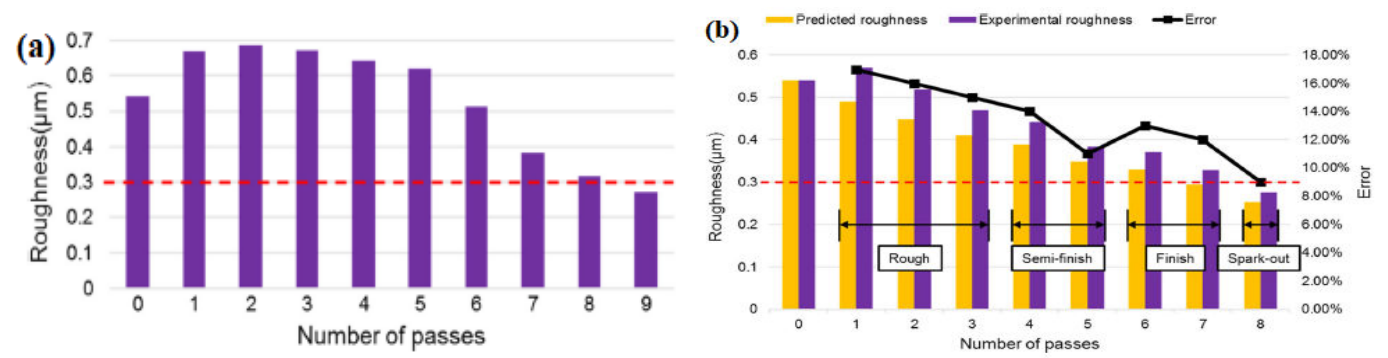

Fig. 19. Obtained results in Chen's work. (a) Roughness evolution in grinding process with empirical optimal parameters and (b) evolution process of the predicted roughness and experimental roughness[80].

Li et al. [81] focused on the effects of laser-assisted grinding parameters on sub- 
surface damage and surface roughness. They used RSM and Genetic Algorithm (GA) to obtain high quality (low surface roughness and depth of subsurface damage) machined surfaces. The results from ANOVA showed that feed rate has the most significant influence on surface roughness, followed by laser power, depth of cut and wheel speed. Kahraman [82] developed a process model of ground surface roughness based on Multi Non-Linear Regression (MNLR). The RSM was used to optimize the effects of wheel speed, depth of cut and feed rate on surface roughness. In their work, Monte Carlo simulation techniques were applied to the experimental data to model the grinding process. The results showed that the introduction of the Monte Carlo uncertainty analysis makes a derived model based on MNLR more realistic, which not only accurately predicted the surface roughness but also improved the service life of the grinding wheel.

In addition, support vector machines (SVM) and other methods have also been employed for predicting ground roughness on a different class of materials $[83,84]$.

\subsection{Taguchi methods}

Taguchi is an experimental design and analysis method based on matrix theory. The principle of Taguchi is to use orthogonal experiments for data processing and to obtain the optimal parameter combination by the calculation and analysis of experimental data $[85,86]$. Taguchi method requires to follow the steps described below:

(1) State the problem and the objectives of the experiment; (2) Select the quality characteristics and the measurement systems; (3) Select the factors and the level for the factors; (4) Select the appropriate orthogonal arrays (OAs), and determine the experimental plan; (5) Conduct experiments and record experimental data; (6) Analyze the experimental results, e.g., using S/N analysis, factor effect, ANOVA, (7) Conduct a confirmation experiment.

The application principle of the Taguchi method in the prediction of grinding surface roughness is to process data by the orthogonal experiments, regarding the error factor as interference factors of fluctuations in prediction results and obtaining the main and secondary factors affecting surface roughness by using $\mathrm{S} / \mathrm{N}$ ratio analysis and 
ANOVA. The sequence of experiments with the combination of parameters and levels is determined by an orthogonal array that determines the number of trials to be performed, ensuring that all levels of all factors are tested in an equal measure. The appropriate array is selected according to the number of factors and levels. For example, consider the regression problem described earlier for optimizing surface roughness given four factors - grinding depth, workpiece infeed speed, wheel speed and wheel diameter. If it is decided to run experiments at four different levels for these four factors, then a full factorial search would require a total of $4^{4}=256$ experiments. In contrast, Taguchi proposed an orthogonal array to determine the effects of individual process parameters. For example, an appropriate orthogonal array for such a scenario (e.g., the L'16 array) comprises 16 trials which test 4 levels of up to 5 different experimental factors. Thus, deploying the appropriate Taguchi orthogonal array (OA) only requires 16 runs to complete the optimization of four levels of four factors and therefore is much more efficient in reducing the number of experimental trials.

Liu et al. [87] developed an automatic grinding system with grinding force control on a CNC machining center. In their work, they employed the Taguchi method for determining ideal combinations of the horizontal feed rate and the desired force value. Results showed that surface roughness decreases with a larger grinding force and with a slow feed rate. Saglam et al. [88] presented an experimental study on the effect of grinding parameters on the roundness error and surface roughness using Taguchi's array. In their experiments, the influence of the work speed, feed rate and depth of cut were investigated. ANOVA and interaction analysis of experimental data showed that roundness and surface roughness could be determined mainly by the work speed and depth of cut unless the feed rate reaches a threshold. Shaji et al. [89] analyzed the effects of process parameters such as speed, feed, infeed and mode of dressing on the force components and surface roughness based on Taguchi's methods. OA, SNR, factor effect analysis and ANOVA were used to determine the optimal combination of processing parameters. Routara et al. [90] proposed an integrated optimization method using Weighted Principal Component Analysis (WPCA) in combination with the Taguchi method to optimize the process parameters of UNS C34000 cylindrical grinding. The 
process parameters chosen in their work were workpiece speed, longitudinal feed and radial infeed and results showed that at a lower speed, surface finish improves due to reduced vibrations. In the work of Köklü et al. [91], the effect of workpiece speed, depth of cut and the number of grooves on surface roughness were investigated using the Taguchi method based on Grey analysis. The results of Grey analysis and ANOVA [92] showed that surface roughness diminishes with a decrease in the workpiece speed, depth of cut and the number of grooves. Patil et al. [93] studied the optimisation of minimum quantity lubrication (MQL) grinding process parameters. The parameters considered in their work were the depth of cut, type of lubricant, feed rate, grinding wheel speed, coolant flow rate, and nanoparticle size. The multi-objective process parameters were optimized by the Taguchi method based on Grey relational analysis. Ming et al. [94] developed a theoretical model of tooth surface roughness based on the grinding track. Tooth surface roughness was considered as a target variable and the machining parameters were optimized by the orthogonal experimental method. In addition, the results from the orthogonal experiments showed that disk wheel spindle speed and feed velocity of the disk wheel have a significant effect on surface roughness.

Chen et al. [95] presented an experimental and theoretical study of surface generation during ultra-precision grinding of hard and brittle materials. In their work, the Taguchi method was employed to study the effect of machining parameters on surface roughness. The results from their experiments showed that the feed rate and the cross-feed distance were the most influential in the surface generation. In addition, the authors found that the spirals around the central area of the workpiece were the primary mechanisms for surface generation. Fig. 20a shows the model of the spiral marks generated by the wheel with micro-vibration. Based on this, the authors developed a theoretical model to predict the single spiral generation and surface roughness. Fig. 20b shows a comparison between predicted and measured surface roughness during grinding of $\mathrm{RB}-\mathrm{SiC}$, which indicates that the model developed in their paper agrees with the experiments. 

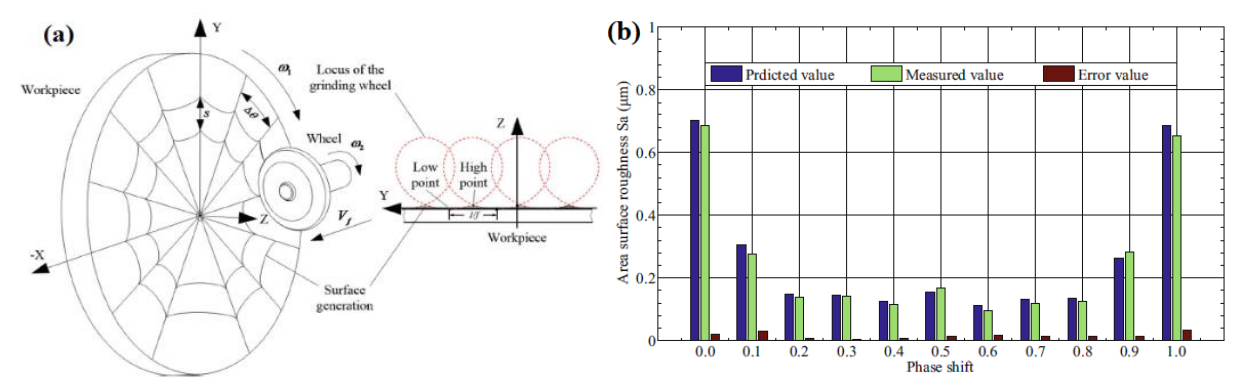

Fig. 20. Method and result in Chen's work. (a) Spiral marks generated by the wheel with microvibration and (b) comparison diagram between predicted and measured area surface roughness [95].

\subsection{Remarks}

The experimental design and analysis methods can help explain the relationship between surface roughness and various influencing parameters. Also, these methods can accurately describe the correlation between various factors. However, these methods suffer from the following two issues:

(i) The regression analysis and Taguchi methods based on the experimental design and analysis can only accurately describe the process within a limited range of selected parameters. When the grinding conditions of the machining process change beyond the design space then the model may no longer be valid; thus, the general applicability of these methods may be poor. Also, the determination of empirical coefficients in regression equations requires a large number of fitting datasets.

(ii) In the extant research, process parameters including grinding wheel velocity, work velocity, and the depth of cut have been selected as the main parameters influencing the surface roughness. However, during the grinding process, parameters such as the workpiece material, the state of the grinding wheel and the movement accuracy of the grinder can also affect the topography of the grinding surface. These parameters are difficult to be employed as design parameters in the experimental design and analysis methods like the process parameters. Therefore, it is difficult for the regression analysis and Taguchi method based experimental design to consider these parameters.

Overall, the generalization ability of methods based on the experimental design and analysis is poor and when applied to the grinding process where the boundary conditions change, the models have limited prediction accuracy. Besides, ground 
surface roughness is a combined effect of interactions of a multitude of factors, including the workpiece material, grinding wheel and grinding conditions. However, most of these parameters are difficult to be quantified in isolation. Therefore, these methods cannot predict surface roughness accurately. However, these methods can study the effects of several factors at one time, investigate the inter-relationships between these factors, and find the most influencing factors, thus reducing the number of experiments required by other data-driven models. For example, it was proved [96] that the Taguchi design of experiments is an efficient scheme for the design of neural networks to predict surface roughness in the grinding of CNT mixed nanofluids [9799].

\section{Artificial intelligence methods}

Artificial intelligence (AI) methods attempt to solve the prediction problem of ground surface roughness by several tools - Artificial Neural Networks (ANNs), Fuzzy Expert Systems (FES) and Genetic Algorithm (GA). The application of AI in the grinding process is conducive to solving the problem of prediction bias caused by the simplification of traditional methods. The most common type of AI methods that have been used in the published papers is the ANN models, improved Neural Networks, and GA [100].

\subsection{Artificial neural networks}

Artificial neural networks (ANNs) are a family of statistical learning models inspired by biological neural networks (the central nervous systems, in particular, the brain) and are used to estimate or approximate functions by considering a large number of inputs [101]. A typical structure of ANN and its calculation process can be seen from Fig. 21. Some attractive characteristics of ANNs are as follows:

(1) Structured: The ANN model is a structured model, as shown in Fig. 21, consisting of several interconnected neurons. The output of one neuron is connected to the input of other neurons according to a certain weight.

(2) Self-adaptation and self-learning ability: The ANN model can find the internal connection between inputs and outputs by training the "sample data", without relying 
on prior knowledge and rules of the problem and has good adaptability.

(3) Generalization ability: The ANN model can process untrained data and obtain the rules of these data. In addition, it can also provide accurate predictions in presence of uncertain data and measurement error.

(4) Nonlinearity: ANNs can achieve non-linear mapping between multiple variables, which provides an effective tool for dealing with these problems.

These characteristics determine the applicability and superiority of neural networks in the prediction of ground surface roughness. The most common type of ANN used in the papers in the past is the back propagation neural network (BPNN). The standard BP network is a data-driven non-linear mapping model which consists of two processes - forward propagation and error back propagation. The essence of the BP network is an unconstrained optimised forward network based on the steepest descent method to find the minimum value of the error function [102].

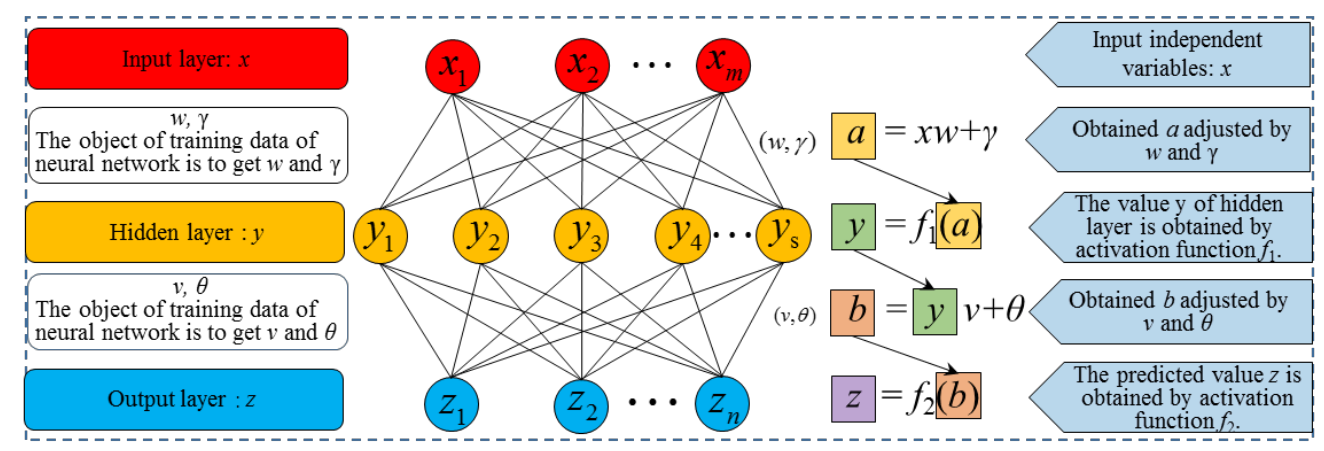

Fig. 21. Structure of neural network.

The principle of neural networks in predicting the ground surface roughness relies on taking the input parameters (process parameters, material parameters and grinding wheel parameters) influencing the surface roughness and then adjust the weight and bias of the network to minimise the objective function by the process of back propagation and complete the training process when obtaining the closest expected output. Finally, the untrained data is processed by the trainer generated in the training process to obtain the prediction value of surface roughness. In recent years, ANN models have been widely used in the prediction of ground roughness.

Matsushima et al. [103] first proposed a hierarchical structure of infrared intelligent machine tool controllers to simulate human operators and discussed the 
significance of offline learning, online learning and self-organizing technologies for the application of intelligent machine tool controllers. Ichida et al. [104] developed a neural network method for grinding pattern recognition and surface quality prediction in silicon nitride. Based on ANN, Zhang et al. [105] designed a fiber-optic sensor system for online inspection of surface roughness. Nabil et al. [97] proposed a method combining the design of the experiments (DOE) and ANN to predict the roughness of the ground surface. In this method, the output data was used to train the ANN, which helped in obtaining a model with higher prediction accuracy. The result showed that the accuracy of the developed ANN model was in good agreement with the results of empirical models developed by previous researchers. Kumar et al. [106] used ANN and DOE to predict the wheel wear and surface roughness during electro-discharge diamond grinding. They also used ANN for prediction of machined surface quality and wheel wear rate for the Electro-discharge diamond grinding process. They developed a relationship between input parameters (pulse current, duty ratio, wheel speed and grit number) and output responses (wheel wear rate and surface roughness). Mukherjee et al. [107] proposed a case-based step-by-step practical method for nonlinear grinding process modelling by using ANN models and provided a comparative study on the conventional linear multivariate models and the non-conventional nonlinear multivariate models based on BPNN. This method was validated by two real life case studies from an automobile engine manufacturing unit. Agrawal et al. [108] developed the relationship between the grinding parameters (pulse current, duty cycle, wheel speed, workpiece speed, depth of cut) and response parameters (Material removal rate, surface roughness) using ANNs in the surface-electrical discharge diamond grinding (S-EDDG) process. Results showed that surface roughness improves with the increase of current, duty factor, depth of cut, and workpiece speed, and diminishes with increasing wheel speed.

\subsection{Improvements in ANN models}

While ANN-based methods have unique advantages in predicting ground surface roughness, they also possess certain disadvantages, for example, slow convergence 
speed and lower accuracy caused by weak global search capability. Therefore, researchers have attempted to improve ANN models in different ways discussed below.

\subsubsection{Adaptive network-based fuzzy inference system}

Fuzzy logic (FL) is a powerful tool for dealing with problems related to imprecision and uncertainty. Considering this aspect, some researchers have considered combining neural network and fuzzy logic inference to develop an adaptive networkbased fuzzy inference system (ANFIS) with strong self-learning ability [109,110]. Fig. 22 shows a typical architecture of ANFIS. In this method, ANN was used to determine various parameters of fuzzy systems, thereby creating or improving a fuzzy system automatically. The essential of the ANFIS is an ANN that can use fuzzy methods to learn faster or perform better.

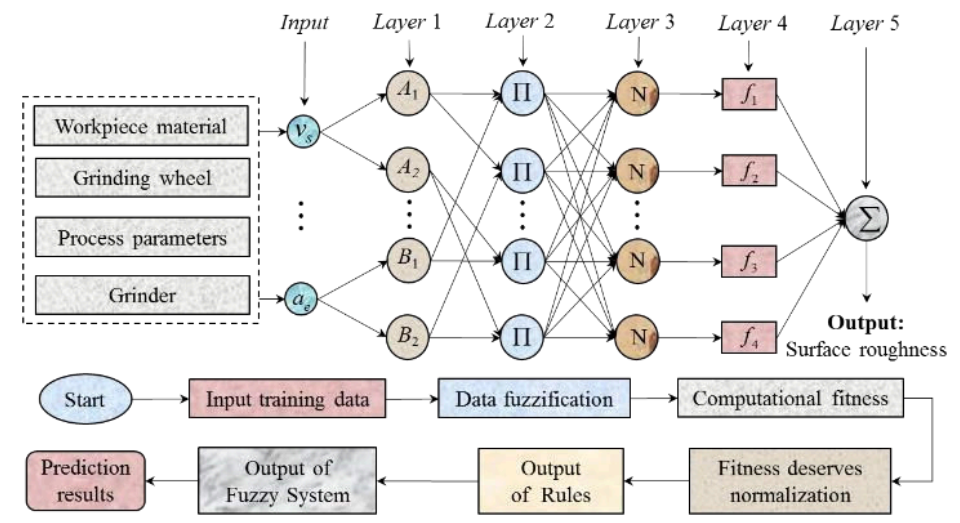

Fig. 22. Structure of the adaptive network-based fuzzy inference system.

The ANFIS combines the advantages of fuzzy logic and neural network, which has obvious advantages in dealing with uncertainty and non-linearity related problems. Therefore, it has been widely used in the prediction of ground surface roughness. Fuzzy basis functions (FBFs) have the capability of combining both numerical data and linguistic information. They were first introduced for ground surface roughness prediction by Wang and Mandel [111] in 1992. Thereafter, fuzzy basis function networks began to be widely used in the prediction of ground roughness. Nagasaka et al. [112] proposed a neuro-fuzzy model based on the group method of data handling. In this model, characteristics of work materials, grinding fluids, factors of wheels, wheel velocity and table feed were used as input variables and the grinding ratio as the resulting output. The authors validated their model within the predicted accuracy by 
using additional data. Nandi et al. [113] proposed a method based on fuzzy basis function neural network (FBF-NN) to model the cylindrical plunge grinding process. This model had three input variables (feed rate, work speed, and wheel speed) and two output variables (power requirement and surface roughness). The corresponding power requirement and surface roughness in the cylindrical plug grinding process were obtained by GA optimisation. Mohanasundararaju et al. [114] developed a surface roughness prediction model for the work roll grinding process based on neural network and fuzzy-based method. This model was validated by grinding the alloy steel using a black carbide silicon grinding wheel. Results showed that this model accurately predicted the surface roughness by utilising small-sized training and testing datasets. Asiltürk et al. [115] developed ANFIS for the prediction of surface roughness and vibrations during cylindrical grinding. To improve online monitoring and prediction, they adopted different neuro-fuzzy parameters during the training process. Experimental validation showed that this system used the gauss-shaped membership function to obtain an online prediction accuracy of 99\%. Prabh et al. [96] proposed that fuzzy neural networks can be used as an alternative to traditional modelling techniques, and predicted the surface roughness of D3 steel grinding by Taguchi-fuzzy logic-neural network analysis. Kumar et al. [116] carried out a full-factorial design of experiments with input process parameters such as work speed, depth of cut and feed rate. Surface roughness and Materials removal rate (MRR) during grinding of Inconel 800 alloy were selected as the output responses. A comparison between three computational methods, namely, ANFIS, regression analysis and neural networks was performed to identify a superior method. Results showed the prediction accuracy of ANFIS to be better. Liang et al. [117] optimized the working parameters of strengthening waterjet grinding by a proposed improved ANFIS system based upon orthogonal experimental design. Their results showed that this system could determine the optimal working parameters with fewer experimental iterations compared to other methods, such as GA, Simulated annealing, and the Taguchi method. Yin et al. [118] proposed a new method based on the compressed air measuring head and hybrid algorithms between ANFIS - Gaussian regression function (GPR) and Taguchi analysis. Fig. 23 shows a logic diagram of the 
scheme employed to monitor the grinding wheel wear and surface roughness in realtime. In this method, the data from the sensors are collected and processed through an adaptive fuzzy neural system integrated with the computer, and then the results of the wheel wear and surface roughness are shown by the display interface.

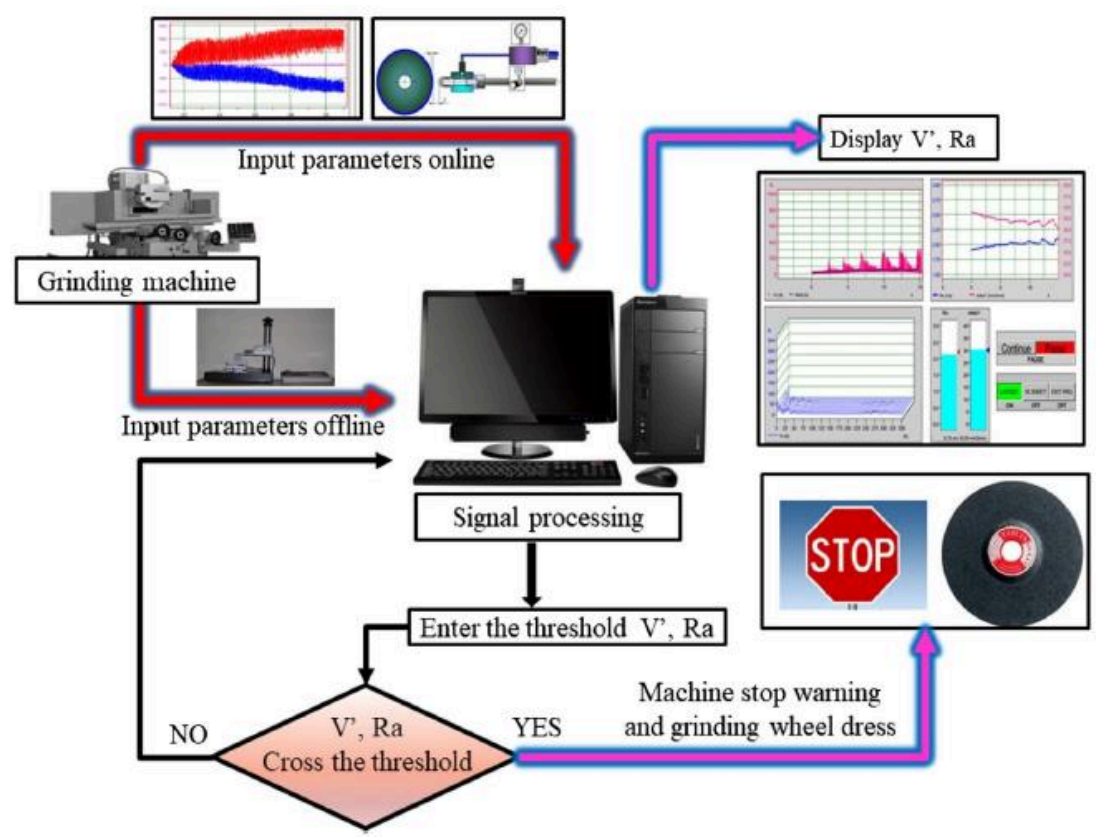

Fig. 23. Logic diagram of the experiment on online monitoring of the grinding wheel wear and the surface roughness [118].

\subsubsection{ANN model based on optimization algorithm}

In addition to Fuzzy logic, some researchers combined neural networks with optimization algorithms, of which genetic algorithm (GA) is the most used optimization method. GA is based on Darwinian's evolution theory on the survival of the fittest and works with a population of individuals, each of which represents the initial weights and bias of the neural network. The global optimal value of individuals can be obtained by the basic operations of the GA (selection, crossover, and mutation). Therefore, combining GA with ANN not only helps select an optimal value within the solution space but also improves the prediction accuracy of the neural network. As shown in Fig. 24, GA was used to perform evolutionary learning to obtain the optimal weights and thresholds, and the output was then used as input for the neural network, which helped achieve global and efficient optimization. 


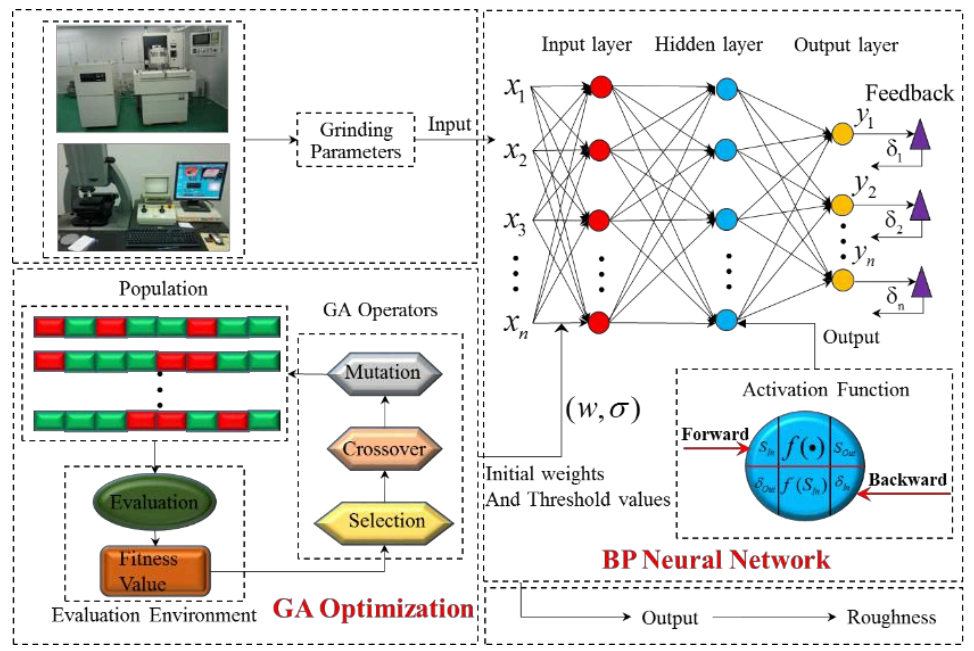

Fig. 24. Structure of genetic neural network.

To summarize previous research works related to ANN application to grinding, we offer tabulated details of grinding wheels, grinding conditions, prediction algorithms, and test results (see Table 3 ).

Table 3 Summary of ANN model based on optimization algorithm in the prediction of ground surface roughness.

\begin{tabular}{|c|c|c|c|c|}
\hline & $\begin{array}{l}\text { Grinding } \\
\text { wheels }\end{array}$ & $\begin{array}{l}\text { Grinding } \\
\text { conditions }\end{array}$ & $\begin{array}{l}\text { Prediction } \\
\text { algorithm }\end{array}$ & Test results \\
\hline Deng et al.[119] & $\mathrm{CBN}$ & $\begin{array}{l}740 \text { different } \\
\text { grinding } \\
\text { conditions }\end{array}$ & $\mathrm{ANN}+\mathrm{GA}$ & $\begin{array}{l}85.42 \% \text { of the prediction error } \\
\text { is between }(+10 \%) .\end{array}$ \\
\hline Yang et al.[120] & $\begin{array}{c}\text { Not } \\
\text { mentioned }\end{array}$ & Fixed & $\mathrm{ANN}+\mathrm{GA}$ & $\begin{array}{l}<3.19 \mu \mathrm{m} \text { prediction error of } \\
\text { absolute peak to valley surface } \\
\text { roughness }\end{array}$ \\
\hline Sedighi et al.[121] & $\begin{array}{l}\text { Aluminum } \\
\text { oxide }\end{array}$ & $\begin{array}{l}16 \text { different } \\
\text { grinding } \\
\text { conditions }\end{array}$ & $\mathrm{ANN}+\mathrm{GA}$ & $\begin{array}{c}<8.64 \% \text { predicting error of } \\
\text { surface } \\
\text { Roughness }\end{array}$ \\
\hline Li et al.[122] & GB70RAP & $\begin{array}{l}18 \text { different } \\
\text { grinding } \\
\text { conditions }\end{array}$ & $\mathrm{ANN}+\mathrm{GA}$ & $\begin{array}{c}<0.02 \mu \mathrm{m} \text { predicting error of } \\
\text { surface roughness }\end{array}$ \\
\hline Chen et al.[123] & $\begin{array}{c}\text { Not } \\
\text { mentioned }\end{array}$ & $\begin{array}{l}24 \text { different } \\
\text { grinding } \\
\text { conditions }\end{array}$ & $\mathrm{ANN}+\mathrm{GA}$ & $\begin{array}{c}\text { The average absolute error is } \\
0.018 \mu \mathrm{m} \text { and the average } \\
\text { relative error is } 3.0 \%\end{array}$ \\
\hline $\mathrm{Xu}$ et al.[124] & $\mathrm{CBN}$ & $\begin{array}{l}9 \text { different } \\
\text { grinding } \\
\text { conditions }\end{array}$ & $\mathrm{ANN}+\mathrm{OA}$ & $\begin{array}{c}<0.03 \mu \mathrm{m} \text { predicting error of } \\
\text { surface } \\
\text { roughness }\end{array}$ \\
\hline Tong et al.[125] & $\begin{array}{l}\text { Not } \\
\text { mentioned }\end{array}$ & $\begin{array}{l}\text { 30different } \\
\text { grinding } \\
\text { conditions }\end{array}$ & $\mathrm{ANN}+\mathrm{PSO}$ & $\begin{array}{c}\text { The prediction roughness error } \\
\text { is less than } 0.3 \%\end{array}$ \\
\hline $\begin{array}{c}\text { Sathyanarayanan et } \\
\text { al.[126] }\end{array}$ & $\mathrm{CBN}$ & $\begin{array}{l}\text { 18different } \\
\text { grinding } \\
\text { conditions }\end{array}$ & $\mathrm{ANN}+\mathrm{MOP}$ & Not mentioned \\
\hline
\end{tabular}

Deng et al. [119] proposed a hybrid ANN and GA model to optimise the process parameters in NC camshaft grinding. In this model, BPNN was developed to map the 
complex nonlinear relationship between process parameters and processing requirements and a GA was used to improve the accuracy and speed based on the ANN model. Yang et al. [120] developed a new model based on GCAOBP (Globally Convergent Adaptive Quick Back Propagation) algorithm and applied GA to train this model. They found that this new model can reduce the local minimum to obtain the global minimum effectively and can accelerate the convergence speed of the learning processes helpfully. Sedighi et al. [121] proposed a method using an integrated genetic algorithm-neural network (GA-NN) system to optimise the creep feed grinding (CFG) process. In this method, wheel speed, workpiece feed and depth of cut were selected as the input variables, and the output responses were surface roughness and MRR. Results showed that this system is an effective tool to determine the optimal process parameters. Li et al. [122] proposed a similar method aiming at predicting the surface finish in cylindrical grinding of steel parts with the GB70RAP wheel. They selected eighteen process parameters as the input parameters. Results showed that this method can accurately predict the surface roughness with the prediction errors of less than $0.02 \mu \mathrm{m}$. Sathyanarayanan et al. [126] studied the neural network modelling and multi-objective optimization of creep feed grinding of superalloys. Chen et al. [123] developed a grinding roughness prediction model based on an evolutionary artificial neural network in the external cylindrical grinding process. Besides, the prediction performances of the BP model, they compared GA-BP model under the same network structure. Results showed that the integration of GA and BP network could improve the convergence speed and prediction accuracy of the roughness model.

In addition to GA, some optimisation methods have also been used to improve the performance of ANN models. Prabhu et al. [67] proposed that the Taguchi design of experiment techniques is an effective tool for the design of neural networks' surface roughness to predict in the grinding process. Xu et al. [124] presented an improved fast Vogl BPNN and orthogonal experiments to optimize the process parameters of spherical grinding. The results showed that the integration of orthogonal experiments, ANN and previous experience on spherical grinding greatly increased the technological design efficiency and improved surface quality. Tong et al. [125] proposed a BPNN model 
optimized by the Particle Swarm Optimization (PSO) to obtain the optimal parameters in the grinding and polishing of M300 steel by an elastic abrasive. Results showed that the roughness of the polished surface got reduced to $0.021 \mu \mathrm{m}$ under the optimal parameter combination conditions, and the prediction error was lower than $0.3 \%$.

\subsection{Optimisation and improvement of ANN structure}

The structure of the ANNs plays a vital role in deciding the performance of the model. Therefore, researchers have tried to obtain more accurate predictions through the internal optimisation of neural networks (i.e., changing the number of hidden layers, the number of hidden layer neurons, and different activation functions). Liao et al. [127] took the example of creep feed grinding of alumina with diamond grinding wheels and designed a BP neural network model with two hidden layers. As shown in Fig. 25, the input of the neurons in the latter layer is the weighted sum of the output of the previous layer, and the features of the previous layer are abstracted in the latter layer. Therefore, the more hidden layers, the higher the level of abstraction of input features. The BP neural network with Boltzmann factor was used to find the global optimal settings for the grinding process, which effectively avoids the model falling into the local minimum point, and this resulted in a more accurate grinding process model than the regression method.

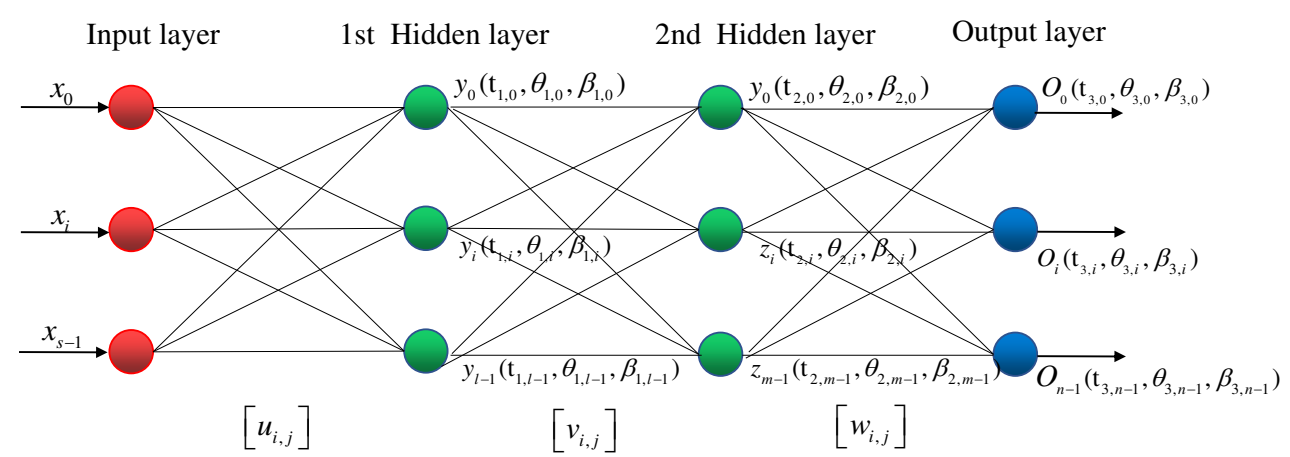

Fig. 25. General structure of a multi-layer perceptron network with two hidden layers[127].

Govindhasamya et al. [128] discussed the effect of the number of hidden layers and different types of activation functions on the performance of a BP network. To optimise the grinding process, a non-linear multi-step prediction model based on the NARX neural network was proposed. Chandrasekaran et al. [129] developed a surface 
roughness prediction model based on the neural network for metal matrix composite cylindrical grinding. They explored the prediction performance of neural networks when log sigmoid (logsig) and tan sigmoid (tansig) were employed as the activation functions of the hidden layer, respectively. Fig. 26a shows that there are significant differences in the prediction accuracy of the BP network with different numbers of hidden layer neurons and types of the activation function, and the ANN structure 4-121 with logsig activation function was found optimum in their study. Sivatte-Adroer et al. [130] proposed an indirect model based on the neural network model for modelling the honing process. They tested the effects of different numbers of layers, several neurons and types of activation functions (logsig and tansig) in the hidden layer on the performance of neural networks. Furthermore, they searched for the best configuration for neural networks by employing two different methods - trial and error and Taguchi DOE. Fig. 26b shows that the best configuration for the network was 100-2-Sigmoidal Tangential, which has 2 layers, 100 neurons in the first hidden layer and Sigmoidal Tangential function was employed as the activation function. Corral et al. [131] proposed a model based on ANN to study the relationship between the honing process parameters and roughness and determined the optimal number of hidden layers and the number of hidden layer neurons. In addition to the grinding parameters, Lipiński at al. [132] considered the material properties (tensile strength, Young's modulus, hardness, thermal expansion and thermal conductivity) and grinding wheel properties (abrasive material, mean grain dimensions, hardness and percentage pore contribution) and researched the performance of ANN with different hidden layer nodes and hidden layer numbers. In a recently published paper [133], the authors of this paper showed a method to determine the activation functions employed in the hidden layer and the output layer of the BP neural network. In this method, virtual data generated from the approximate physical model was used to train the BP neural network with different activation functions to obtain the effect of activation function on the performance of BP neural network. This method was validated by the published grinding experimental data and results showed that it is an effective way to select the activation functions for BP neural network of ground surface roughness. 

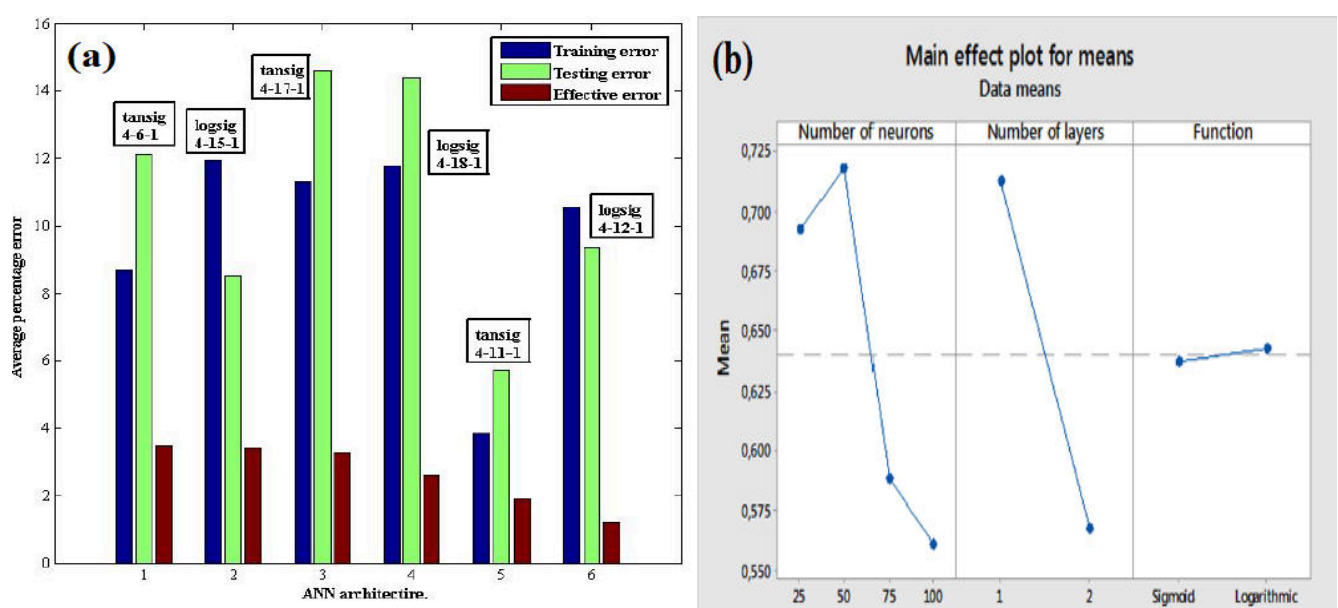

Fig. 26. Performance of the NN with different structures. (a) Selection of optimal NN structure [129] and (b) minimum quantization error of the model under different parameters [130].

\subsection{Other AI methods for surface roughness prediction}

Researchers have also used other AI methods to predict the ground surface roughness. These methods were aimed at developing a mathematical model of grinding roughness and then to obtain the best combination of the grinding process parameters by using intelligent algorithm optimization. Saravanan et al. [134] proposed a GA-based method to achieve optimisation using a multi-objective function model. They concluded that the performance of genetic algorithms is better than traditional quadratic programming. Gopal et al. [135] focused on the effect of depth of cut, feed rate, grit size and grit density on surface finish and damage produced during grinding of silicon carbide and developed a GA-based procedure to optimize the grinding conditions. Nandi et al. [136] developed a method for the automatic design of the fuzzy logic controller (FLC) based on GA to predict the power requirement and surface finish in grinding. Gholami et al. [137] presented a mathematical model to estimate the surface roughness based on experimental investigations. The surface finish, total grinding time and the production cost subjected to the constraints of production rate and wheel wear parameters were selected as the objectives. Optimal values of wheel speed, workpiece speed and depth of cut were obtained by the non-dominated sorting genetic algorithm (NSGA II). To optimise the grinding parameters and improve the efficiency of abrasive belt grinding, Huang et al. [138] proposed a novel trajectory planning method based on the diploid genetic algorithm. The effectiveness of the method was validated by an 
abrasive belt grinding experiment of the aero-engine blade. In addition to GA, Mohamad et al. [139] proposed the Cuckoo algorithm [140] to predict the surface roughness of Abrasive Water Jet (AWJ). They developed several prediction models to obtain the best-predicted value of surface roughness. Results showed that the Cuckoo algorithm has better performance than ANN and support vector machines. Baskar et al. [141] developed an Ant Colony Algorithm (ACO) to optimize grinding conditions, viz. depth of dressing, wheel speed, workpiece speed, and lead of dressing. It was found that ACO outperformed the results from two conventional techniques, quadratic programming techniques and the GA. Rao [142] proposed an advanced optimization technique, the "Jaya" algorithm, to solve the optimization problem in engineering, and compared its performance with other optimization techniques, such as GA and PSO.

\subsection{Remarks}

The review of AI-based papers shows that researchers have tried to predict ground surface roughness of different materials using AI. These methods only allow us to identify a particular pattern in the data but do not reveal any complex scientific insight into the grinding process. While many AI models have been developed, there are many open questions.

(i) The construction of the indicator system: As shown in Fig. 27, the result of the ground surface roughness is the effect of interactions of a multitude of factors, including the geometry, kinematics, mechanics and thermal parameters of grinders, tools, and parts. However, most of these parameters are difficult to determine in isolation due to time-variant processes and randomness. The current prediction models of ground surface roughness based on AI methods ignore the time factor of the grinding process. Therefore, these models can only predict the final value of ground surface roughness and cannot help achieve the real-time online detection of surface roughness. 


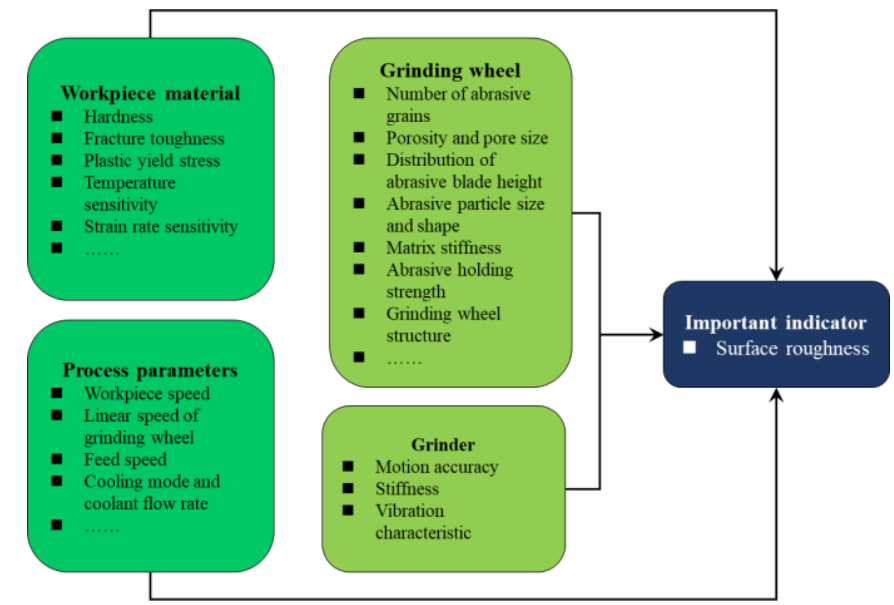

Fig. 27. Process parameters which can influence the ground surface roughness.

(ii) Data acquisition and processing: The accuracy of the neural network training depends on the size of the sample data. The larger the sample data, the higher the prediction accuracy. However, the number of experimental samples required by AI models increases exponentially with the increase in the number of variables. Additionally, parameters such as the state of the grinding wheel and the movement accuracy of the grinder are difficult to be employed as design parameters in AI methods. For example, in the prediction model of ground surface roughness, if the state of the grinding wheel is considered, different grinding wheels need to be customized during the design of experiments, which will increase the cost of experiments.

(iii) The topology of the AI methods: The success of AI model application, in general, depends significantly on the proper selection of the topology of the model. For example, the topology of the ANN, and the importance of this is also reflected in Section 5.3 where researchers often employed ANN with a different number of hidden layers, different hidden layer nodes and different types of activation functions to solve the same task. However, there is no commonly used method to determine these parameters. For example, as the number of hidden layers increases, the learning ability of the ANN will increase, but the learning efficiency will reduce, so it is difficult to establish an accurate and efficient structure. In terms of different hidden layer nodes, it is often determined by Eq. (9).

$$
m=\sqrt{n+l}+\alpha
$$

where $n$ is the number of nodes of the input layer, $l$ is the nodes of the output layer, and 
$\alpha$ is a constant from 1 to 10 . This equation can only determine a range for the nodes of the hidden layer, so it is often selected arbitrarily or at most by trials or tuning.

(iv) Guidance for new processes: Since AI models treat the complex physical mechanism as a black box, these methods cannot reveal the scientific mechanisms or selection tools to guide the development of new processes.

Overall, artificial intelligence (AI) is considered as a fundamental way to computing which parallels the remarkable ability of the human mind to reason and learn in an environment of uncertainty and imprecision. Machine learning is considered to be one of the most successful AI methods and typical machine learning techniques can be divided into two categories - supervised learning and unsupervised learning. Both these techniques are data-driven AI methods used to model the complex relationship between input and output. Fig. 28 shows the difference between supervised learning and unsupervised learning. Supervised learning performs feature extraction and model development in a separate manner, which relies heavily on expert domain knowledge. On the contrary, unsupervised learning integrates feature learning and model development in one model by selecting different kernels or tuning the parameters via end to end optimization. All these processes are finished by the model itself with the minimum human inference.

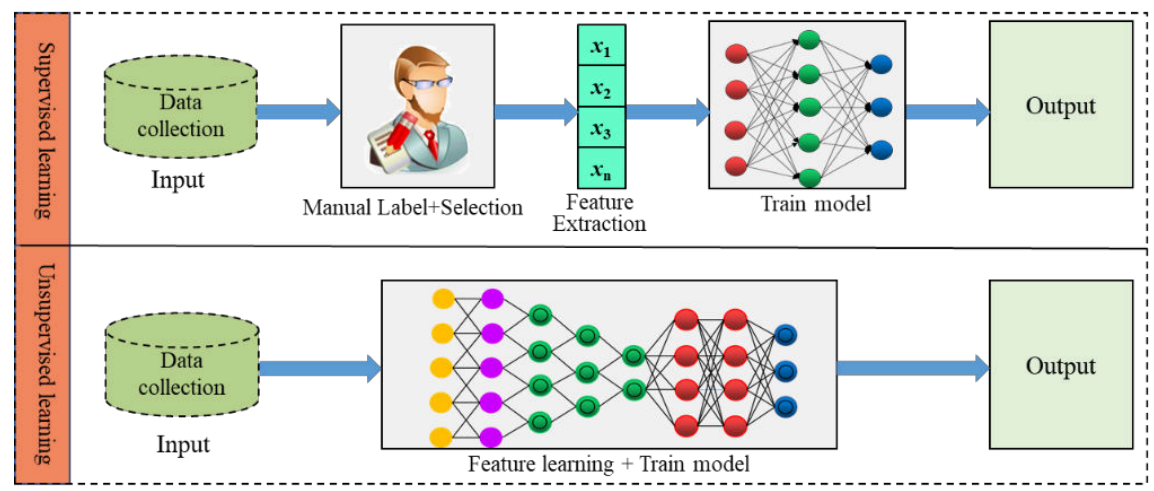

Fig. 28. Comparison between the supervised learning and unsupervised learning.

These prediction methods indicate that supervised learning has been already used widely to predict ground surface roughness. However, these models follow a similar approach as describe above i.e. first one selects the indicators, and then regression methods such as ANN and ANFIS are used to model a nonlinear mapping function 
between these indicators and surface quality. However, considering the challenges, such as the construction of the indicator system, real-time prediction and data acquisition and processing, it is difficult to meet the need for precision grinding of diverse materials. Compared to supervised learning, unsupervised learning, such as a convolutional neural network (CNN) [143] and sparse autoencoder (SAE) [144] can achieve adaptive feature learning, which is helpful to improve the adaptability of prediction methods. Moreover, layer-by-layer feature learning in these methods is more likely to help uncover essential features hidden in the monitoring data and improve prediction accuracy. Therefore, unsupervised learning is a more powerful tool for the prediction of surface roughness.

\section{Current challenges and future trends}

\subsection{Open research questions}

Existing research methods applied in grinding technology are yet to mature to fully meet the needs of future development (as outlined in various remarks in each of the previous three sections), and it is therefore imperative to propose and develop new methods or strategies that can predict ground surface roughness more accurately and in real time. This is going to be a consistent requirement of digitalized and smart manufacturing in the future. Fig. 29 shows the trend of development in the prediction of the grinding surface roughness. It shows how integrating the physical space, information space and empirical knowledge in real-time is a prerequisite to achieve efficient control of the surface quality.

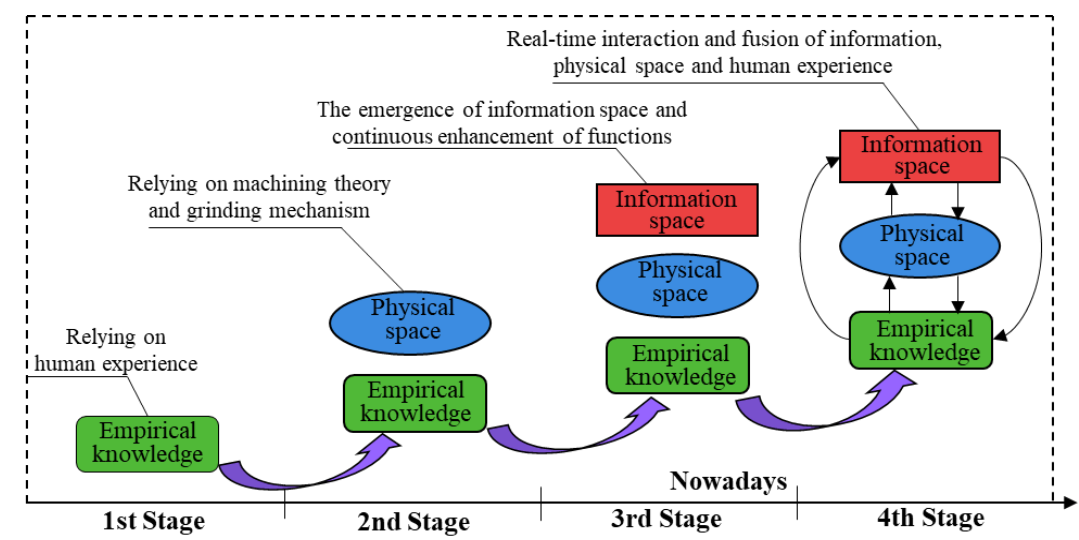

Fig. 29. The development trend of the grinding surface roughness prediction models.

According to the review of methods for predicting ground surface roughness, we find that the methods developed to date have gone through the following three stages 
of evolution.

(i) First stage: Management and control of the grinding process at this stage were achieved by human sense, skills and experience. These methods were inaccurate and had low efficiency apart from being skill dependent.

(ii) Second stage: Researchers developed models based on the grit-workpiece microscopic interaction mechanisms to predict ground surface roughness. However, the research and management of the grinding process in this period were limited by the physical space.

(iii) Third stage: With the development of computers, the data information space in the grinding process appeared. Various data-driven grinding surface roughness prediction models were developed based on the information space. Nevertheless, the physical space and information space at this stage are independent of each other and they lack continuous and real-time interconnection and interoperability. Human skills are still a dominant method to achieve robust control during the grinding process.

The current methods for predicting ground surface roughness are still in the first three stages. The management of the grinding process is in a nascent stage and the methods for controlling the product quality in almost all shop floors still passively and statically rely on the measurement of undulations (roughness) on the workpiece surface. Although these methods can guide us to solve the quality of machining, it is difficult to meet the requirements in terms of hardware cost, labor cost and efficiency for the future processing needs of diverse and high-quality materials. As the future unfolds, researchers need to develop methods for the efficient grinding of a wide variety of materials, which not only focus on accurate and real-time prediction of surface roughness but also reveal the unknown physical mechanisms. These efforts can guide us towards improved parameter selection and the development of new processes. For example, the fusion of the model developed based on the machining theory and the machine learning method is an effective way to solve the development of high-speed grinding process for diversified materials in the future. In this model, the mechanism 
researches can effectively reduce variables, thereby reducing the need for data samples required by the machine learning models, which can reduce the cost of experiments and improve the efficiency and stability of machine learning models.

\subsection{The necessity of real-time prediction of surface roughness}

In recent years, with the continuous development of technology and the emergence of new materials, industrial demand has changed from metals to a series of hard and brittle materials and semiconductor materials such as sapphire, zirconia, silicon carbide, and gallium arsenide. As a widely used surface quality index, surface roughness is closely related to the processing parameters in the grinding process which is a crucial indicator of the quality of machining $[145,146]$. The efficient manufacturing of surfaces with lower roughness or better quality is essential for business sustainability. Real-time prediction of surface roughness helps to understand the condition of the workpiece and to make adjustments to eliminate the downstream product waste which is aligned to the principles of smart manufacturing and Industry 4.0.

\subsection{A roadmap for the future}

Extant research shows that the result of the grinding process is influenced by many dynamically changing factors, the contact area between the abrasive grits and the workpiece, stochastic distribution of the grits, wear of the grinding wheel and contact stiffness variations and inclusions in the workpiece (granular boundaries, imperfections and dislocation nucleation). It is hard to achieve deterministic quantitative measures for multivariable systems such as precision grinding. However, manufacturing machines are increasingly being equipped with sensors and communication capabilities under the vision of Industry 4.0 [147]. Various advanced data analytics methods such as data mining, data visualization and deep learning [148,149] provide the basis for computational intelligence in the information space. Moreover, advances in sensors and the Industrial Internet of things (IIoT) [150] provide foundations for linking the physical world of machines to the knowledge world of computation. Such integration and convergence into a physical-information world of manufacturing give rise to a new focus on Digital Twin, which provides a complete digital footprint of a physical system 
from design and development through the end of the product lifecycle [151]. Digital Twin takes advantage of physics-based simulation models and data driven intelligence to offer valuable clues on how the state of the workpiece changes during the grinding. Therefore, digital twins can provide an effective way to achieve the rapid development of diverse and high-quality material processing schemes via communication and interaction of physical space, information space, and empirical knowledge.

Fig. 30 shows the structure of a near-term futuristic multi-information information fusion system for predicting ground surface roughness. Specifically, sensor technology would be very useful to acquire raw processing signals from the processing machines and manufacturing, for example, dynamometers and accelerometers $[152,153]$ can be used to measure the cutting forces and the machine tool vibration in the grinding process. Also, acoustic emission technology $[154,155]$ has also proved to be an effective tool to detect changes in the state of the workpiece during the grinding process. These signals can be used to develop more sophisticated deep learning models to achieve near-zero error manufacturing. Combined with physical knowledge and human empirical knowledge, information can be directed towards achieving an autonomous system for predicting surface roughness.

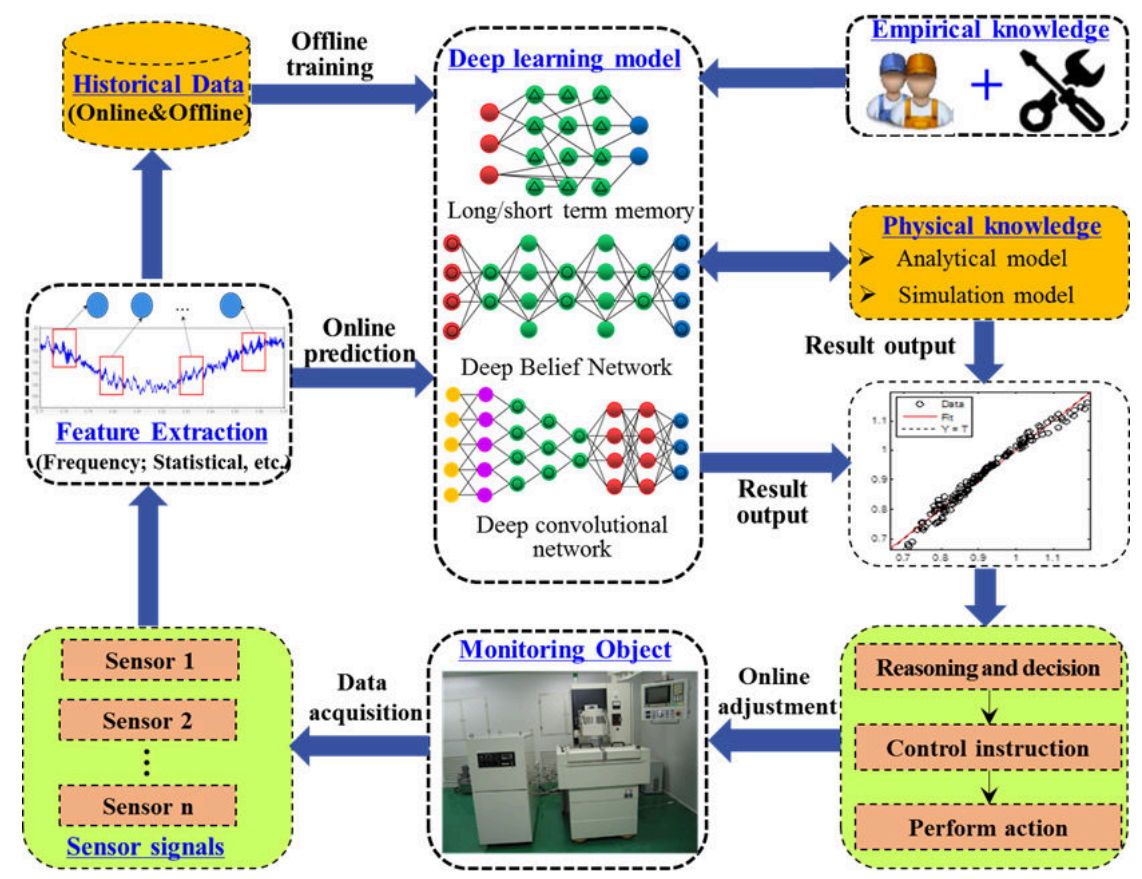

Fig. 30. Multi-information fusion structure for surface roughness prediction.

\section{Concluding Remarks}


Grinding is one of the most widely used precision machining operations. Measurement of ground surface roughness relies on carrying out a large number of heuristic experimental trials depending on the skill of the operator and this results in wastage of time, energy and materials. In the age of digitalisation (with new sensor developments) and the machines becoming smarter with the induction of Industry 4.0, it is now high time to revisit the extant grinding models to assess the possibility of deterministically predicting ground roughness with a view to (i) eliminating waste (ii) know the optimum process parameters beforehand and avoiding the productive time wasted in pre-setting the machining conditions and (iii) using the same principles to develop the feedback control loop to adjust the quality of machining by offsetting the wear in real-time.

With this broad view in mind, this paper summarizes the extant literature to shed new insights on the various models available to the researchers to predict ground surface roughness. Based on this review, various methods developed or proposed so far were categorized into three categories: (i) physics-based models (numerical simulation and analytical models based on machining theory), (ii) statistical and empirical models based on experimental design and analysis and (iii) artificial intelligence assisted models.

While current research has advanced in many areas in these three categories, several exciting research avenues are still open and need further research efforts. These new research directions will inform the arena of complex part manufacturing and help address the next level of manufacturing challenges such as Precision-at-scale fabrication and Total thickness variation (TTV) across the diameter of a wafer. In this paper, we discuss the advantages and disadvantages of these models and propose a roadmap to help achieve high efficiency in the precision grinding of materials.

Overall, this paper synthesizes and reviews the methods and allied theories on the prediction of ground surface roughness and provides a state-of-the-art, in-depth and comprehensive reference for researchers who are exploring issues surrounding surface topography in grinding. We hope that future research will benefit from the ideas proposed in this paper and play an increasingly significant role in the development of 
Intelligent Manufacturing in the age of digitalisation.

\section{Research Data statement}

Data sharing is not applicable to this article as no new data were created or analyzed in this study.

\section{Acknowledgments:}

All authors appreciate the financial support from the National Natural Science Foundation of China (51875078, 51991372), and the Science Fund for Creative Research Groups of NSFC of China (51621064). SG acknowledges the financial support provided by the UKRI via Grants No.: (EP/L016567/1, EP/S013652/1, EP/S036180/1, EP/T001100/1 and EP/T024607/1), Royal Academy of Engineering via Grants No. (IAPP18-19\295, TSP1332 and EXPP2021\1\277), EU Cost Actions (CA15102, CA18125, CA18224 and CA16235) and Newton Fellowship award from the Royal Society (NIF $\backslash \mathrm{R} 1 \backslash 191571)$. SG is particularly thankful to European Regional Development Funds (ERDF) sponsored A2i project at LSBU that has catalysed several industrial partnerships.

The work used Isambard Bristol, UK supercomputing service accessed by Resource Allocation Panel (RAP) grant as well as ARCHER resources (Project e648).

\section{References:}

[1] Comley P, Morantz P, Shore P. Grinding metre scale mirror segments for the E-ELT ground based telescope. CIRP Ann-Manuf Technol. 2011;60(1):379-82.

[2] Shore P, Cunningham C, DeBra D, Evans C, Hough J, Gilmozzi R. Precision engineering for astronomy and gravity science. CIRP-Ann Manuf Technol. 2010;59(2):694-716.

[3] Liu W, Deng Z, Shang Y, Wan L. Effects of grinding parameters on surface quality in silicon nitride 
grinding. Ceram Int. 2017;43(1B):1571-77.

[4] Huang H, Yin L, Zhou L. High speed grinding of silicon nitride with resin bond diamond wheels. J Mater Process Tech. 2003;141(3):329-36.

[5] Teicher U, Ghosh A, Chattopadhyay AB, Künanz K. On the grindability of Titanium alloy by brazed type monolayered superabrasive grinding wheels. Int J Mach Tool Manufact. 2006;46(6):620-22.

[6] Lin B, Zhou P, Wang Z. Analytical Elastic - Plastic Cutting Model for Predicting Grain Depth-ofCut in Ultrafine Grinding of Silicon Wafer. J Manuf Sci E-ASME. 2018;140(12): 121001.

[7] Quirynen M, Bollen C. The influence of surface-roughness and surface-free energy on supragingival and subgingival plaque-formation in man A review of the literature. J Clin Periodontol. $1995 ; 22(1): 1-14$.

[8] Karakoca S, Yilmaz H. Influence of Surface Treatments on Surface Roughness, Phase Transformation, and Biaxial Flexural Strength of Y-TZP Ceramics. J Biomed Mater Res B. 2009;91B(2):930-37.

[9] Albers A, Reichert S. On the influence of surface roughness on the wear behavior in the running-in phase in mixed-lubricated contacts with the finite element method. Wear. 2017;376(B):1185-93.

[10] Carmignato S, Aloisi V, Medeossi F, Zanini F, Savio E. Influence of surface roughness on computed tomography dimensional measurements. CIRP-Ann Manuf Technol. 2017;66(1):499-502.

[11] Benardos PG, Vosniakos GC. Predicting surface roughness in machining: a review. Int J Mach Tool Manufact. 2003;43(8):833-44.

[12] Tönshoff HK, Peters J, Paul II. Modelling and Simulation of Grinding Processes. CIRP-Ann Manuf Technol. 1992;2(41):677-88.

[13] Brinksmeier E, Aurich JC, Govekar E, Heinzel C, Hoffmeister HW, Klocke F. Advances in Modeling and Simulation of Grinding Processes. CIRP-Ann Manuf Technol. 2006;55(2):667-96.

[14] Aurich JC, Kirsch B. Kinematic simulation of high-performance grinding for analysis of chip parameters of single grains. CIRP-Ann Manuf Technol. 2012;5(3):164-74.

[15] Kassen G. Beschreibung der elementaren Kinematik des Schleifvor-ganges (Description of the Fundamental Kinematics of the Grinding Process), Germany: RWTH Aachen University, 1969.

[16] Law SS, Wu SM. Simulation study of the grinding process. Transactions of the ASME. Series B, Journal of Engineering for Industry. 1973;95(4):972-78.

[17] Koshy P, Ives LK, Jahanmir S. Simulation of diamond-ground surfaces. Int J Mach Tool Manufact. 
1999;39(9):1451-70.

[18] Gong YD, Wang WS, Wang B. The simulation of grinding wheels and ground surface roughness based on virtual reality technology. J Mater Process Tech. 2002;129(1):123-26.

[19] Liu Y, Warkentin A, Bauer R, Gong Y. Investigation of different grain shapes and dressing to predict surface roughness in grinding using kinematic simulations. Prec Eng. 2013;37(3):758-64.

[20] Wang S, Li C, Zhang D, Jia D, Zhang Y. Modeling the operation of a common grinding wheel with nanoparticle jet flow minimal quantity lubrication. Int J Adv Manuf Technol. 2014;74(5):835-50.

[21] Siebrecht T, Biermann D, Ludwig H, Rausch S, Kersting P, Blum H. Simulation of grinding processes using finite element analysis and geometric simulation of individual grains. Prod Eng. 2014;8(3):345-53.

[22] Chen H, Tang J. A model for prediction of surface roughness in ultrasonic-assisted grinding. Int J Adv Manuf Technol. 2015;77(1-4):643-51.

[23] Jiang JL, Ge PQ, Bi WB, Zhang L, Wang DX, Zhang Y. 2D/3D ground surface topography modeling considering dressing and wear effects in grinding process. Int J Mach Tool Manufact. 2013;74:2940.

[24] Sun S, Tang J, Shao W, Chen C, Liu Y. Research on the matching relationship between ultrasonicassisted grinding parameters and workpiece surface roughness. Int J Adv Manuf Technol. 2019;102(1-4):487-96.

[25] Chen H, Wang Q. A novel approach to simulate surface topography based on motion trajectories and feature theories of abrasive grains. Int J Adv Manuf Technol. 2018;99(5-8):1467-80.

[26] Li HN, Yu TB, Zhu LD, Wang WS. Analysis of loads on grinding wheel binder in grinding process: insights from discontinuum-hypothesis-based grinding simulation. Int $\mathbf{J}$ Adv Manuf Technol. 2015;78(9-12):1943-60.

[27 Li HN, Yu TB, Zhu LD, Wang WS. Modeling and simulation of grinding wheel by discrete element method and experimental validation. Int J Adv Manuf Technol. 2015;81(9-12):1921-38.

[28] Osa JL, Sánchez JA, Ortega N, Iordanoff I, Charles JL. Discrete-element modelling of the grinding contact length combining the wheel-body structure and the surface-topography models. Int J Mach Tool Manufact. 2016;110:43-54.

[29] Osa JL, Ortega N, Vidal G, Fernandez-Gauna B, Carballo A, Tolosa I. Future of the discrete element method in the modelling of grinding wheels. Eng Computation. 2018;35(6):2255-71. 
[30] Chakrabarti S, Paul S. Numerical modelling of surface topography in superabrasive grinding. Int J Adv Manuf Technol. 2008;39(1-2):29-38.

[31] Chen X, Rowe WB. Analysis and simulation of the grinding process, part 2: mechanics of grinding. Int J Mach Tool Manufact. 1996;8(36):883-96.

[32] Nguyen TA, Butler DL. Simulation of surface grinding process, part 2: interaction of the abrasive grain with the workpiece. Int J Mach Tool Manufact. 2005;45(11):1329-36.

[33] Zhou WH, Tang JY, Chen HF, Shao W. A comprehensive investigation of surface generation and material removal characteristics in ultrasonic vibration assisted grinding. Int $\mathrm{J}$ Mech Sci. 2019;156:14-30.

[34] Chen HF, Tang JY, Zhu C. A new approach to modeling the surface topography in grinding considering ploughing action. Mach Sci Technol. 2018;22(4):604-20.

[35] Zhou WH, Tang JY, Chen HF, Zhu C, Shao W. A comprehensive investigation of plowing and grain-workpiece micro interactions on 3D ground surface topography. Int $\mathbf{J}$ Mech Sci. 2018;144:639-53.

[36] Wu J, Cheng J, Gao CC, Yu T, Guo ZZ. Research on predicting model of surface roughness in small-scale grinding of brittle materials considering grinding tool topography. Int J Mech Sci. 2020;166:105263.

[37] Wang Y, Guangheng D, Zhao J, Dong Y, Zhang X, Jiang X, et al. Study on key factors influencing the surface generation in rotary ultrasonic grinding for hard and brittle materials. J Manuf Process. 2019;38:549-55.

[38] Arif M, Zhang XQ Z, Rahman M, Kumar S. A predictive model of the critical undeformed chip thickness for ductile - brittle transition in nano-machining of brittle materials. Int $\mathrm{J}$ Mach Tool Manufact. 2013;64:114-22.

[39] Jiang C, Cheng J, Wu T. Theoretical model of brittle material removal fraction related to surface roughness and subsurface damage depth of optical glass during precision grinding. Prec Eng. $2017 ; 49: 421-27$

[40] Li HN, Yu TB, Zhu LD, Wang WS. Analytical modeling of ground surface topography in monocrystalline silicon grinding considering the ductile-regime effect. Arch Civ Mech Eng. 2017;17(4):880-93.

[41] Huang N, Yan Y, Zhou P, Kang R, Guo D. Analytical Elastic - Plastic Cutting Model for Predicting 
Grain Depth-of-Cut in Ultrafine Grinding of Silicon Wafer. Japanese Journal of Applied. 2019;58:086501.

[42] Huang N, Yan Y, Zhou P, Kang R, Guo D, Goel S. Elastic recovery of monocrystalline silicon during ultra-fine rotational grinding. Prec Eng. 2020;65:64-71.

[43] Reichenbach GS, Mayer JE. The role of chip thickness in grinding. Transactions of the ASME. $1956 ; 78: 847-60$

[44] Snoeys R, Peter J. The significance of chip thickness in grinding. CIRP-Ann-Manuf Techn. $1974 ; 23: 227-37$

[45] Huang H, Yin L, Zhou L. High speed grinding of silicon nitride with resin bond diamond wheels. J Mater Process Tech. 2003;141(3):329-36.

[46] Pahlitzsch G. Helmerdig H. Determination and significance of chip thickness in grinding. Workshop Technol. 1943;12:397-401.

[47] Shaw MC, Reichenbach GS. The role of chip thickness in grinding. Trans. ASME. 1956;18:847-50.

[48] Malkin S. Theory and Applications of Machining with Abrasives.New York: Industrial Press,1989.

[49] Brown RH, Saito B. Local elastic deflections in grinding. CIRP-Ann Manuf Technol. 1971;1(19):105-13.

[50] Basuray PKSB. A simple model for evaluating surface roughness in fine grinding. Int J Mach Tool Manufact. 1980;3-4(20):265-73.

[51] Zhou X, Xi F. Modeling and predicting surface roughness of the grinding process. Int J Mach Tool Manufact. 2002;42(8):969-77.

[52] Hou ZB, Komanduri R. On the mechanics of the grinding process-Part I. Stochastic nature of the grinding process. Int J Mach Tool Manufact. 2003;43(15):1579-93.

[53] Darafon A, Warkentin A, Bauer R. 3D metal removal simulation to determine uncut chip thickness, contact length, and surface finish in grinding. Int J Adv Manuf Technol. 2013;66(9-12):1715-24.

[54] Jiang J, Ge P, Hong J. Study on micro-interacting mechanism modeling in grinding process and ground surface roughness prediction. Int J Adv Manuf Technol. 2013;67(5-8):1035-52.

[55] Younis MA. Alawi H. Probabilistic analysis of the surface grinding process. T Can Soc Mech Eng. 1984;4(8):208-13.

[56] Hecker RL, Liang SY. Predictive modeling of surface roughness in grinding. Int J Mach Tool Manufact. 2003;43(8):755-61. 
[57] Lal G, MC S. Wear of single abrasive grain in fine grinding. Grindng Conf. Pittsburgh,USA. 1972. Carnegie-Mellon University, 1972.

[58] Agarwal S, Rao PV. A probabilistic approach to predict surface roughness in ceramic grinding. Int J Mach Tool Manufact. 2005;45(6):609-16.

[59] Agarwal S, Rao PV. A new surface roughness prediction model for ceramic grinding. P I Mech Eng B-J Eng. 2005;219(11):811-19.

[60] Agarwal S, Venkateswara Rao P. Modeling and prediction of surface roughness in ceramic grinding. Int J Mach Tool Manufact. 2010;50(12):1065-76.

[61] Agarwal S, Venkateswara Rao P. Predictive modeling of undeformed chip thickness in ceramic grinding. Int J Mach Tool Manufact. 2012;56:59-68.

[62] Khare SK, Agarwal S. Predictive Modeling of Surface Roughness in Grinding. Procedia CIRP. $2015 ; 31: 375-80$.

[63] Ding W, Dai C, Yu T, Xu J, Fu Y. Grinding performance of textured monolayer CBN wheels: Undeformed chip thickness nonuniformity modeling and ground surface topography prediction. Int J Mach Tool Manufact. 2017;122:66-80.

[64] Zhang Y, Fang C, Huang G, Xu X. Modeling and simulation of the distribution of undeformed chip thicknesses in surface grinding. Int J Mach Tool Manufact. 2018;127:14-27.

[65] Agrawal A, Goel S, Rashid WB. Prediction of surface roughness during hard turning of AISI 4340 steel (69 HRC). Appl Soft Comput. 2015;30:279-86.

[66] Goel S, Kalamdhad A S, Agrawal A. Parameter optimisation for producing fired bricks using organic solid wastes. J Clean Prod. 2018; 205:836-44.

[67] Prabhu S, Uma M, Vinayagam BK. Surface roughness prediction using Taguchi-fuzzy logic-neural network analysis for CNT nanofluids based grinding process. Neural Comput Appl. 2015;26(1):4155.

[68] Kanakarajan P, Sundaram, S. Prediction of the surface roughness and wheel wear of modern ceramic material (A12O3) during grinding using multiple regression analysis model. Indian J Eng Mater S. 2017;24(3):182-86.

[69] Tripathi D. Optimization of surface grinding parameters on aisi d2 steel using response surface methodology. Journal of Industrial engineering. 2017;6(X).

[70] Pashmforoush F, Delir Bagherinia R. Influence of water-based copper nanofluid on wheel loading 
and surface roughness during grinding of Inconel 738 superalloy. J Clean Prod. 2018;178:363-72.

[71] Chandrasekaran M, Muralidhar M, Krishna CM, Dixit US. Application of soft computing techniques in machining performance prediction and optimization: a literature review. Int J Adv Manuf Technol. 2010;46(5-8):445-64.

[72] Wang L, Chan LC, Lee TC. Process modeling of controlled forming with time variant blank holder force using RSM method. Int J Mach Tool Manufact. 2007;47(12-13):1929-40.

[73] Kiyak M, Cakir O. Study of surface quality in dry and wet external cylindrical grinding. International Journal of Computational Materials Science and Surface Engineering. 2010;3(1):12-23.

[74] Kwak J, Sim S, Jeong Y. An analysis of grinding power and surface roughness in external cylindrical grinding of hardened SCM440 steel using the response surface method. Int J Mach Tool Manufact. 2006;46(3-4):304-12.

[75] Kwak J. Application of Taguchi and response surface methodologies for geometric error in surface grinding process. Int J Mach Tool Manufact. 2005;45(3):327-34.

[76] Mohanasundararaju N, Sivasubramanian R, Alagumurthi N. Optimisation of work roll grinding using Response Surface Methodology and evolutionary algorithm. Int J Manuf Research. 2008;2(3):236-51.

[77] Neşeli S, Asiltürk İ, Çelik L. Determining the optimum process parameter for grinding operations using robust process. J Mech Sci Technol. 2012;26(11):3587-95.

[78] Zhao T, Shi Y, Lin X, Duan J, Sun P, Zhang J. Surface roughness prediction and parameters optimization in grinding and polishing process for IBR of aero-engine. Int J Adv Manuf Technol. $2014 ; 74(5-8): 653-63$

[79] Rudrapati R, Pal PK, Bandyopadhyay A. Modeling and optimization of machining parameters in cylindrical grinding process. Int J Adv Manuf Technol. 2016;82(9-12):2167-82.

[80] Chen Z, Li X, Wang L, Zhang S, Cao Y, Jiang S, et al. Development of a hybrid particle swarm optimization algorithm for multi-pass roller grinding process optimization. Int $\mathrm{J}$ Adv Manuf Technol. 2018;99(1-4):97-112.

[81] Li Z, Zhang F, Luo X, Chang W, Cai Y, Zhong W, et al. Material removal mechanism of laserassisted grinding of RB-SiC ceramics and process optimization. J Eur Ceram Soc. 2019;39(4):70517.

[82] Kahraman MF, Öztürk S. Experimental study of newly structural design grinding wheel considering 
response surface optimization and Monte Carlo simulation. Measurement. 2019;147:106825.

[83] Mat Deris A, Mohd Zain A, Sallehuddin R. Hybrid GR-SVM for prediction of surface roughness in abrasive water jet machining. Meccanica. 2013;48(8):1937-45.

[84] Guo J. Surface roughness prediction by combining static and dynamic features in cylindrical traverse grinding. Int J Adv Manuf Technol. 2014;75(5-8):1245-52.

[85] Tsai FC, Yan BH, Kuan CY, Huang FY. A Taguchi and experimental investigation into the optimal processing conditions for the abrasive jet polishing of SKD61 mold steel. Int J Mach Tool Manufact. 2008;48(7-8):932-45.

[86] Rashid WB, Rashid WB, Goel S, Goel S, Davim JP, Davim JP, et al. Parametric design optimization of hard turning of AISI 4340 steel (69 HRC). Int J Adv Manuf Technol. 2016;82(1):451-62.

[87] Liu CH, Chen A, Chen CCA, Wang Y. Grinding force control in an automatic surface finishing system. J Mater Process Tech. 2005;170(1-2):367-73.

[88] Saglam H, Unsacar F, Yaldiz S. An experimental investigation as to the effect of cutting parameters on roundness error and surface roughness in cylindrical grinding. Int J Prod Res. 2005;43(11):230922.

[89] Shaji S, Radhakrishnan V. Analysis of process parameters in surface grinding with graphite as lubricant based on the Taguchi method. J Mater Process Tech. 2003;141(1):51-59.

[90] Routara BC, Mohanty SD, Datta S, Bandyopadhyay A, Mahapatra SS. Combined quality loss (CQL) concept in WPCA-based Taguchi philosophy for optimization of multiple surface quality characteristics of UNS C34000 brass in cylindrical grinding. Int J Adv Manuf Technol. 2010;51(14):135-43.

[91] Köklü U. Optimisation of machining parameters in interrupted cylindrical grinding using the Greybased Taguchi method. Int J Comput Integ M. 2013;26(8):696-702.

[92] Jagadish, Bhowmik S, Ray A. Prediction of surface roughness quality of green abrasive water jet machining: a soft computing approach. J Intell Manuf. 2015;30:2965-2979.

[93] Patil PJ, Patil CR. Analysis of process parameters in surface grinding using single objective Taguchi and multi-objective grey relational grade. Perspectives in Science. 2016;8:367-69.

[94] Ming X, Gao Q, Yan H, Liu J, Liao C. Mathematical modeling and machining parameter optimization for the surface roughness of face gear grinding. Int J Adv Manuf Technol. 2017;90(912):2453-60. 
[95] Chen SS, Cheung CF, Zhang FH. An experimental and theoretical analysis of surface generation in the ultra-precision grinding of hard and brittle materials. Int J Adv Manuf Technol. 2018;97(5$8): 2715-29$.

[96] Prabhu S, Uma M, Vinayagam BK. Surface roughness prediction using Taguchi-fuzzy logic-neural network analysis for CNT nanofluids based grinding process. Neural Comput Appl. 2015;26(1):4155.

[97] Fredj NB, Amamou R. Ground surface roughness prediction based upon experimental design and neural network models. Int J Adv Manuf Technol. 2006;31(1-2):24-36.

[98] Çaydaş U, Hasçalık A. A study on surface roughness in abrasive waterjet machining process using artificial neural networks and regression analysis method. J Mater Process Tech. 2008;202(13):574-82.

[99] Labib AW, Keasberry VJ, Atkinson J, Frost HW. Towards next generation electrochemical machining controllers: A fuzzy logic control approach to ECM. Expert Syst Appl. 2011;38(6):7486-93.

[100] Nakai ME, Junior HG, Aguiar PR, Bianchi EC, Spatti DH. Neural Tool Condition Estimation in The Grinding of Advanced Ceramics. Ieee Lat Am T. 2015;13(1):62-68.

[101] Korosec M, Balic J, Kopac J. Neural network based manufacturability evaluation of free form machining. Int J Mach Tool Manu. 2005;45(1):13-20.

[102] Fuh KH, Wang SB. Force modeling and forecasting in creep feed grinding using improved BP neural network. Int J Mach Tool Manu. 1997;37(8):1167-78.

[103] Matsushima K, Sata T. Development of intelligent machine tool. J. Faculty Eng., Univ. Tokyo. 198035):299-314.

[104] Ichida Y, Zouaghi N, Kishi K. Analysis of ductile mode ground surface of optical-glass by atomicforce microscopy. In: Usui (Ed). Jspe Publication Series 1994; 491-96.

[105] Zhang KW, Butler C, Yang QP, Lu YC. A fiber optic sensor for the measurement of surface roughness and displacement using artificial neural networks. IEEE $\mathrm{T}$ Instrum Meas. 1997;46(4):899-902.

[106] Kumar S, Choudhury SK. Prediction of wear and surface roughness in electro-discharge diamond grinding. J Mater Process Tech. 2007;191(1-3):206-09.

[107] Mukherjee I, Ray PK. A case-based and practical approach for multivariate modeling of grinding 
process. Int J Adv Manuf Technol. 2009;45(3-4):245-60.

[108] Agrawal SS, Yadava V. Modeling and Prediction of Material Removal Rate and Surface Roughness in Surface-Electrical Discharge Diamond Grinding Process of Metal Matrix Composites. Mater Manuf Process. 2013;28(4):381-89.

[109] Horikawa S, Furuhashi T, Uchikawa Y. On Fuzzy Modeling using fuzzy neural networks with the backpropagation algorithm. IEEE T Neural Networ. 1992;3(5):801-06.

[110] Nauck D, Klawonn F, Kruse R. Combining neural networks and fuzzy controllers. In: Klement EP, Slany W, editors.1993. p. 35-46.

[111] Wang LX, Mende JM. Fuzzy basis functions, universal approximation, and orthogonal leastsquares learning, IEEE T Neural Networ. 1992;3(5):807-14.

[112] Nagasaka K, Ichihashi H, Leonard R. Neuro-fuzzy GMDH and its application to modelling grinding characteristics. Int J Prod Res. 1995;33(5):1229-40.

[113] Nandi AK, Banerjee MK. FBF-NN-based modelling of cylindrical plunge grinding process using a GA. J Mater Process Tech. 2005;162-163:655-64.

[114] Mohanasundararaju N, Sivasubramanian R, Gnanaguru R, Alagumurthy N. A Neural Network and Fuzzy-Based Methodology for the Prediction of Work Roll Surface Roughness in a Grinding Process. Int J Comput Met Eng Sci Mech. 2008;9(2):103-10.

[115] Asiltürk İ, Tinkir M, El Monuayri H, Çelik L. An intelligent system approach for surface roughness and vibrations prediction in cylindrical grinding. Int J Comput Integ M. 2012;25(8):750-59.

[116] Sudheer Kumar Varma N, Varma I R P K, Rajesh S, Sita Rama Raju K, Murali Krishnam Raju VV. Prediction of surface roughness and MRR in grinding process on Inconel 800 alloy using neural networks and ANFIS. Materials Today: Proceedings. 2018;5(2):5445-51.

[117] Liang Z, Liao S, Wen Y, Liu X. Working parameter optimization of strengthen waterjet grinding with the orthogonal-experiment-design-based ANFIS. J Intell Manuf. 2019;30(2):833-54.

[118] Yin S, Nguyen D, Chen F, Tang Q, Duc LA. Application of compressed air in the online monitoring of surface roughness and grinding wheel wear when grinding Ti-6Al-4V titanium alloy. Int J Adv Manuf Technol. 2019;101(5):1315-31.

[119] Deng ZH, Zhang XH, Liu W, Cao H. A hybrid model using genetic algorithm and neural network for process parameters optimization in NC camshaft grinding. Int $\mathbf{J}$ Adv Manuf Technol. 2009;45(9-10):859-66. 
[120] Yang QQ, Jin J. Study on machining prediction in plane grinding based on artificial neural network. In: Xiaogang J, Yangguang L, Da R, editors. Proceedings 2010 IEEE International Conference on Intelligent Systems and Knowledge Engineering,Hangzhou,China. 2010. 442-44.

[121] Sedighi M, Afshari D. Creep feed grinding optimization by an integrated GA-NN system. J Intell Manuf. 2010;21(6):657-63.

[122] Li GF, Liu J, Yang SX. On-line Prediction of Surface Roughness in Cylindrical Traverse Grinding Based on BP+GA Algorithm. 2011 Second International Conference on Mechanic Automation and Control Engineering, Hohhot, China. 2011. 1456-9.

[123] Chen LQ. Grinding roughness prediction model based on evolutionary artificial neural network. Com-Int Manuf Systems. 2013;19(11):2854-63.

[124] Xu KZ, Hu DJ, Wei CJ. Vogl fast BP network and orthogonal experiment method in optimization of sphere grinding process parameters. Journal of Shanghai Jiaotong University. 2009;43(12):1956-61.

[125] Tong X, Wu X, Zhang F, Ma G, Zhang Y, Wen B, et al. Mechanism and Parameter Optimization in Grinding and Polishing of M300 Steel by an Elastic Abrasive. Materials. 2019;12(3):340.

[126] Sathyanarayanan G, Joseph lin I, Chen M. Neural network modelling and multiobjective optimization of creep feed grinding of superalloys. Int J Prod Res. 1992;30(10):2421-38.

[127] Liao TW, Chen LJ. A neural-network approach for grinding processes - modeling and optimization. Int J Mach Tool Manu. 1994;34(7):919-37.

[128] Govindhasamy JJ, McLoone SF, Irwin GW, French JJ, Doyle RP. Neural modelling, control and optimisation of an industrial grinding process. Control Eng Pract. 2005;13(10):1243-58.

[129] Chandrasekaran M, Devarasiddappa D. Artificial neural network modeling for surface roughness prediction in cylindrical grinding of Al-SiCp metal matrix composites and ANOVA analysis. Adv Prod Eng Manag. 2014;9(2):59-70.

[130] Sivatte-Adroer M, Llanas-Parra X, Buj-Corral I, Vivancos-Calvet J. Indirect model for roughness in rough honing processes based on artificial neural networks. Prec Eng. 2016;43:505-13.

[131] Sivatte-Adroer M, Buj-Corral I, Llanas-Parra X. Neural network modelling of Abbott-Firestone roughness parameters in honing processes. Int J Surf Sci Eng. 2017;11(6):512-30.

[132] Lipiński D, Bałasz B, Rypina Ł. Modelling of surface roughness and grinding forces using artificial neural networks with assessment of the ability to data generalisation. Int J Adv Manuf Technol. 
2018;94(1-4):1335-47.

[133] Pan YH, Wang YH, Zhou P, Yan Y, Guo DM. Activation functions selection for BP neural network model of ground surface roughness. J Intell Manuf. 2020.

[134] Saravanan R, Sachithanandam M. Genetic Algorithm (GA) for Multivariable Surface Grinding Process Optimisation Using a Multi-objective Function Model. Int J Adv Manuf Tech. 2001;17(5):330-38.

[135] Venu Gopal A, Venkateswara Rao P. Selection of optimum conditions for maximum material removal rate with surface finish and damage as constraints in $\mathrm{SiC}$ grinding. Int $\mathbf{J}$ Mach Tool Manufact. 2003;43(13):1327-36.

[136] Nandi AK, Pratihar DK. Automatic design of fuzzy logic controller using a genetic algorithm - to predict power requirement and surface finish in grinding. J Mater Process Tech. 2004;148(3):288300.

[137] Gholami MH, Azizi MR. Constrained grinding optimization for time, cost, and surface roughness using NSGA-II. Int J Adv Manuf Technol. 2014;73(5-8):981-88.

[138] Huang Z, Song R, Wan C, Wei P, Wang H. Trajectory planning of abrasive belt grinding for aeroengine blade profile. Int J Adv Manuf Technol. 2019;102(1-4):605-14.

[139] Mohamad A, Zain AM, Bazin NEN, Udin A. A process prediction model based on Cuckoo algorithm for abrasive waterjet machining. J Intell Manuf. 2015;26(6):1247-52.

[140] Yang XS, Deb S. Cuckoo Search via Levy Flights. Nature I\& Biologically Inspired Computing (NaBIC 2009) Coimbatore: India,2009. 210-14.

[141] Baskar N, Saravanan R, Asokan P, Prabhaharan G. Ants colony algorithm approach for multiobjective optimisation of surface grinding operations. Int J Adv Manuf Technol. 2004;23(5-6):31117.

[142] Rao, R. Jaya: an advanced optimization algorithm and its engineering applications. Switzerland: Springer International Publishing AG, 2019.

[143] Schmidt J, Marques MRG, Botti S, Marques MAL. Recent advances and applications of machine learning in solid-state materials science. Npj Comput Mater. 2019;5(1):1-36.

[144] Shi CM, Panoutsos G, Luo B, Liu H, Li B, Lin X. Using Multiple-Feature-Spaces-Based Deep Learning for Tool Condition Monitoring in Ultraprecision Manufacturing. IEEE T Ind Electron. 2019;66(5):3794-803. 
[145] Dong ZG, Zheng FF, Zhu XL, Kang RK, Zhang B, Liu ZQ. Characterization of material removal in ultrasonically assisted grinding of SiCp/Al with high volume fraction. Int J Adv Manuf Technol. 2017;93(5-8):2827-39.

[146] Kivak T. Optimization of surface roughness and flank wear using the Taguchi method in milling of Hadfield steel with PVD and CVD coated inserts. Measurement. 2014;50:19-28.

[147] Alexopoulos K, Nikolakis N, Chryssolouris G. Digital twin-driven supervised machine learning for the development of artificial intelligence applications in manufacturing. Int J Comput Integ M. 2020;33:1-11.

[148] Wang Y, Liu M, Zheng P, Yang H, Zou J. A smart surface inspection system using faster R-CNN in cloud-edge computing environment. Adv Eng Inform. 2020;43:101037.

[149] Dai HN, Wang H, Xu GQ, Wan JF, Imran M. Big data analytics for manufacturing internet of things: opportunities, challenges and enabling technologies. Enterp Inf Syst-Uk. 2019:1-25.

[150] Caesarendra W. An AWS Machine Learning-Based Indirect Monitoring Method for Deburring in Aerospace Industries Towards Industry 4.0. App Sci. 2018;11(8):2165.

[151] Wang JJ, Ye JL, Gao R X. Digital Twin for rotating machinery fault diagnosis in smart manufacturing. Int J Prod Res: Special Issue: Sustainable Cybernetic Manufacturing. 2019;57(12):3920-34.

[152] Wang J, Wang P. Enhanced particle filter for tool wear prediction. J Manuf Syst. 2015;36:35-45.

[153] Wang JJ, Yan JX ,Li C, Gao RX. Deep heterogeneous GRU model for predictive analytics in smart manufacturing: Application to tool wear prediction. Comput Ind. 2019;111:1-14.

[154] Guo W. An intelligent monitoring system of grinding wheel wear based on two-stage feature selection and Long Short-Term Memory network. J Eng Manuf. 2019;13(223):2436-46.

[155] Nguyen D, Yin S, Tang Q, Son PX, Duc LA. Online monitoring of surface roughness and grinding wheel wear when grinding Ti-6Al-4V titanium alloy using ANFIS-GPR hybrid algorithm and Taguchi analysis. Prec Eng. 2019;55:275-92. 
2020-11-06

New insights into the methods for predicting ground surface roughness in the age of digitalisation

\section{Pan, Yuhang}

\section{Elsevier}

Pan Y, Zhou P, Yan Y, et al., (2021) New insights into the methods for predicting ground surface roughness in the age of digitalisation. Precision Engineering, Volume 67, January 2021 , pp. 393-418

https://doi.org/10.1016/j.precisioneng.2020.11.001

Downloaded from Cranfield Library Services E-Repository 